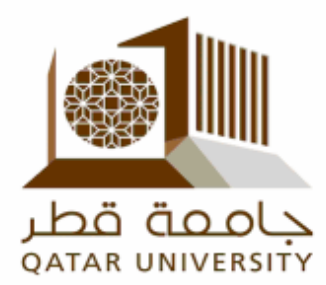

Novel Cellular Materials for Energy Absorption Applications

By

Mohammed Mudassir

Mahmoud Mansour

Department of Mechanical and Industrial Engineering

College of Engineering

Qatar University

Fall 2016 
Novel Cellular Materials for Energy Absorption Applications

\section{By}

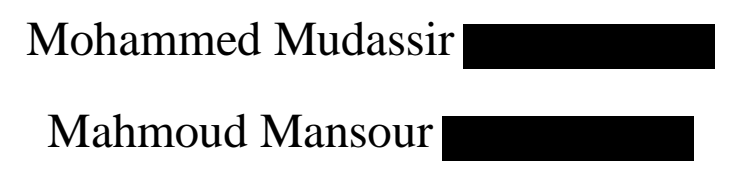

THIS REPORT IS SUBMITTED IN PARTIAL FULFILLMENT OF THE REQUIREMENT FOR THE DEGREE OF BACHELOR OF SCIENCE IN MECHANICAL ENGINEERING

Supervisor: Dr. Faris Tarlochan

Department of Mechanical and Industrial Engineering

College of Engineering

Qatar University

Fall 2016 


\section{DECLARATION}

We hereby declare that this project report is based on our original work except for citations and quotations which have been duly acknowledged. We also declare that it has not been previously and concurrently submitted for any other degree or award at Qatar University or other institutions.

Signature :

Name : Mohammed Mudassir

ID No. :

Date $\quad: \quad 09 / 01 / 2017$

Signature :

Name $\quad:$ Mahmoud Mansour

ID No. : :

Date $\quad: \quad 09 / 01 / 2017$ 


\section{Qatar University Library}

Doha

QATAR

\section{Permission to Make Photocopies of Report}

We, Mohammed Mudassir and Mahmoud Mansour, declare that the report entitled Novel Cellular Materials for Energy Absorption Applications

belongs to us. The contents of this report may be used by anyone for academic purposes of teaching, learning, and research, only. Qatar University is permitted to make photocopies of this document for the same academic purposes.

Date: $\quad 09 / 01 / 2017$

Name: $\quad$ Mohammed Mudassir

Name: Mahmoud Mansour 


\section{APPROVAL FOR SUBMISSION}

We certify that this project report entitled "NOVEL CELLULAR MATERIALS FOR ENERGY ABSORPTION APPLICATIONS" was prepared by MOHAMMED MUDASSIR and MAHMOUD MANSOUR have met the required standard for submission in partial fulfillment of the requirements for the award of Bachelor of Science in Mechanical Engineering at Qatar University.

Approved by,

Signature :

Supervisor: Dr. Faris Tarlochan

Date

Signature :

Examiner I:

Date

Signature :

Examiner II:

Date

Signature :

Senior Project Coordinator: Dr. John-John Cabibihan

Date 
Dedication

To our parents. 


\section{ACKNOWLEDGEMENTS}

We would like to thank our dead supervisor Dr. Faris Tarlochan for his extensive mentorship and support. We would also like to extend our appreciation to the Department of Mechanical and Industrial Engineering for all the support they have given us in completing this project. We acknowledge the financial support of Qatar National Research Fund given to us through grant number UREP17-151-2-044. 


\title{
ABSTRACT \\ Novel Cellular Materials for Energy Absorption Applications
}

\author{
Mohammed Mudassir and Mahmoud Mansour
}

Qatar University, 2016

Supervisor(s): Dr. Faris Tarlochan

Cellular materials such as metal foams are porous, lightweight structures that exhibit good energy absorption properties. They have been used for many years in various applications including energy absorption. Traditional cellular structures do not have consistent pore sizes and their behaviors and properties such as failure mechanisms and energy absorption are not always same even within the same batch. This is a major obstacle for their applications in critical areas where consistency is required. With the popularity of additive manufacturing, new interest has garnered around fabricating metal foams using this technology. It is necessary to study the possibility of designing cellular structures with additive manufacturing and their energy absorbing behavior before any sort of commercialization for critical applications is contemplated. The primary hypothesis of this senior project is to prove that energy absorbing cellular materials can be designed. Designing in this context is much like how a car can be designed to carry a certain number of passengers. To prove this hypothesis, the paper shows that the geometry is a key factor that affects energy absorption and that is possible to design the geometry in order to obtain certain behaviors and properties as desired. Much like designing a car, it requires technical expertise, ingenuity, experience and learning curve for designing cellular structures. It is simple to come with a design, but not so much when the design in constrained by stringent requirements for energy absorption and failure behaviors. The scope was limited to the study of metal foams such as the ones made from aluminum and titanium. The primary interest has been academic rather than finding ways to commercialize it. The study has been carried out using simulation and experimental verification has been suggested for future work. Nevertheless, the numerical or simulation results show that energy absorbing cellular structures can be designed that exhibit good energy absorption comparable to traditional metal foams but perhaps with better consistency and failure behaviors. The specific energy absorption was found to be $18 \mathrm{~kJ} / \mathrm{kg}$ for aluminum metal foams and $23 \mathrm{~kJ} / \mathrm{kg}$ for titanium metal foams. The average crushing force has been observed to be around $70 \mathrm{kN}$ for aluminum and around $190 \mathrm{kN}$ for titanium. These values are within the acceptable range for most traditional metal foams under similar conditions as simulated in this paper. 


\section{Table of Contents}

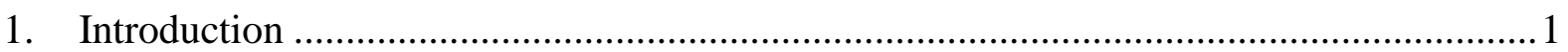

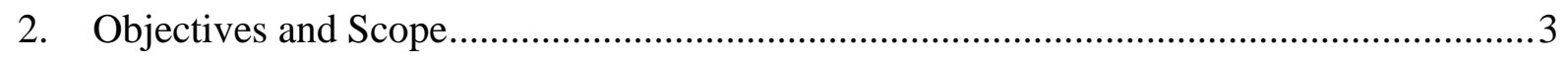

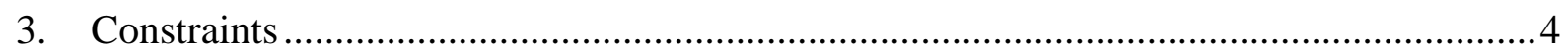

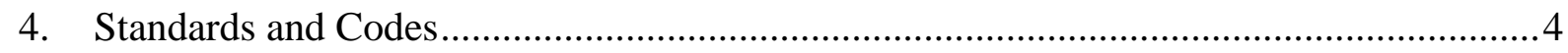

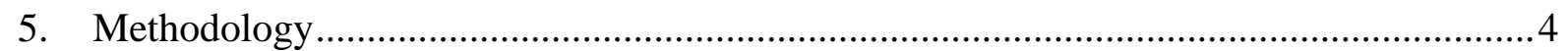

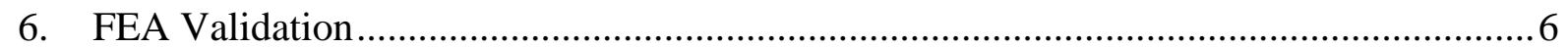

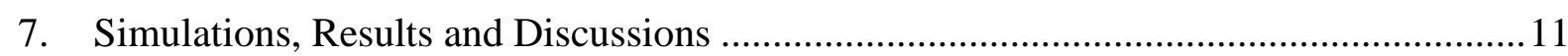

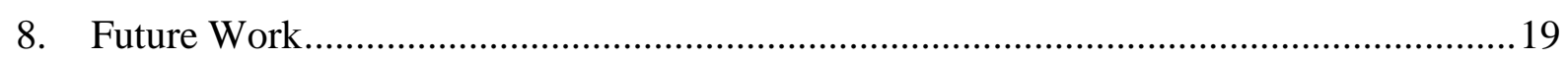

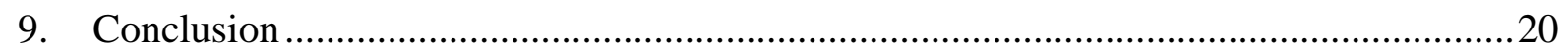

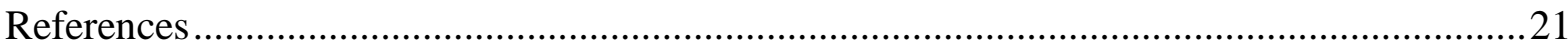

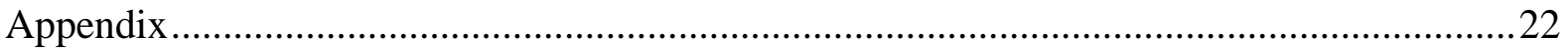

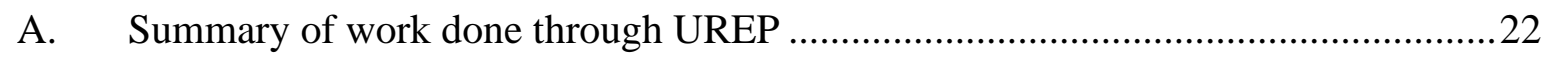

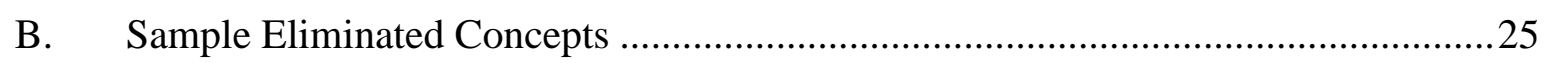




\section{List of Tables}

Table 1. Johnson-Cook parameters for aluminum and titanium

Table 2. Tables shows the matrix of the combinations used for materials, lengths and thickness totaling 72

Table 3. Table shows how the problems were broken down and corrected using incremental learning

Table 4. Section thicknesses shown in Figure 15. This varies from one design to another according to the geometry. The thickness unit is in [mm].

\section{List of Figures}

Figure 1. A metal foam fabricated using traditional manufacturing exhibits non-uniform porosity

Figure 2. A lightweight cellular structure fabricated by Boeing (Source: Boeing) 2

Figure 3. A metal foam under compressive loading (Source: Afsaneh Rabiei at North Carolina

State University)

Figure 4. A typical force-displacement curve obtained from the compressive test of cellular structures

Figure 5. Ideal force-displacement curve 3

Figure 6. Incremental learning curve shown in flowchart form used for this project 6

Figure 7. The assembly of a cellular structure 8

Figure 8. ABAQUS unit system (Source: ABAQUS Explicit 6.14 User Manual) 9

Figure 9. Mesh size vs time taken for simulations 10

Figure 10. Number of elements vs time taken for simulation 10

Figure 11. Sample designs that have been used to find the good geometries for energy absorption 11

Figure 12. The selected best three designs based on specific energy absorption 11

Figure 13. The thicknesses were modified in the walls and the struts 12

Figure 14. Evolution of cellular structure designs from UREP to senior 16

Figure 15. The tedious process of assigning the materials throughout the cellular structures 17

Figure 16. Different thicknesses in the shells -truly engineered for application. 17

Figure 17. Different sections within the cellular structure have different shell thickness. It is

$\begin{array}{ll}\text { truly customized. } & 18\end{array}$

Figure 18. The same design produced a similar force-displacement curve even for different materials indicating it is the geometry that is responsible for this behavior 19

Figure 19. Progressive collapse of the final design that also produced the curves in Figure 17

Figure 20. STL files for the samples created using SolidWorks 20 


\section{Introduction}

What are cellular materials? How can they be novel? What are energy absorption applications? Perhaps these questions were the reader's initial reaction to the title "Novel cellular materials for energy absorption applications." Cellular materials are lightweight materials such as foams. They are typically marked by their hollow, porous structures and small weight to volume ratios. They are easy to carry and does not require as much fuel as their solid counterparts. They can be novel in their designs and applications. Among their many properties, energy absorption is an important one. When discussing novel cellular materials for energy absorption applications, the key idea revolves around designing these lightweight structures for absorbing energies. For instance, is it easier to punch with boxing gloves on than with bare hands. The gloves contain materials that absorb some of the reaction forces from the target object thereby reducing the pain felt by the hand. Similarly, cellular materials can be used to absorb energy in some critical applications, thereby protecting whatever in enclosed by them. Cellular materials can be made from many different base materials such as metals, polymers, or even composites. The choice of the material depends upon the applications. Metal cellular materials have been known and used for energy absorption applications for many years. However, when they are fabricated using traditional manufacturing processes they yield irregular pore sizes and non-homogeneous properties. Even within the same batch of production, each sample is expected to be different than the next - reducing their reliability. The Figure 1 below shows a traditionally manufactured metal foam. Notice the irregular pore sizes and the randomness of the pore distribution. Nevertheless, it is much lighter than a solid occupying the same volume.

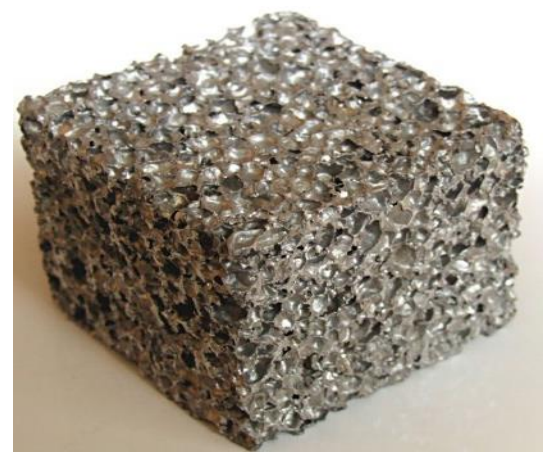

Figure 1. A metal foam fabricated using traditional manufacturing exhibits non-uniform porosity

With the rise of additive manufacturing, it is now possible to design metal cellular structures that have regular shapes and designs. Thus, the properties are predicted to be much more consistent even though there will still be statistical variations. Additive manufacturing uses metal powders and laser-melting technologies to fabricate cellular structures. For instance, the American airline company Boeing has fabricated a metal cellular structure that is very light as shown in the Figure 2 below. The picture has been released by Boeing to highlight that the metal structure is ninety-nine percent air. So light that it can be supported on top of a dandelion without crushing it. 


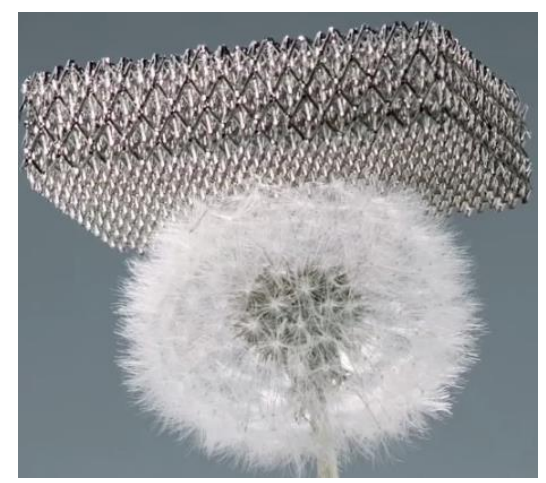

Figure 2. A lightweight cellular structure fabricated by Boeing (Source: Boeing)

While these high-end tech companies are investing a lot of money if developing this technology, additive manufactured metal foams are still far from being a consumer product. In this undergrad research, a humble study has been carried out to show how metal cellular structures can be designed for energy absorption.

These metal cellular structures are also called micro lattice, metal foams, honeycombs and so on based on the way they are designed and fabricated. The main concern for this paper is to design such structures in order to achieve good energy absorption. Typically, the energy absorption of metal foams can be found from the force-displacement curve obtained from a compression test. The Figure 3 below shows a metal foam going under compression test. Figure 4 shows what a typical force-displacement curve looks like from such tests.

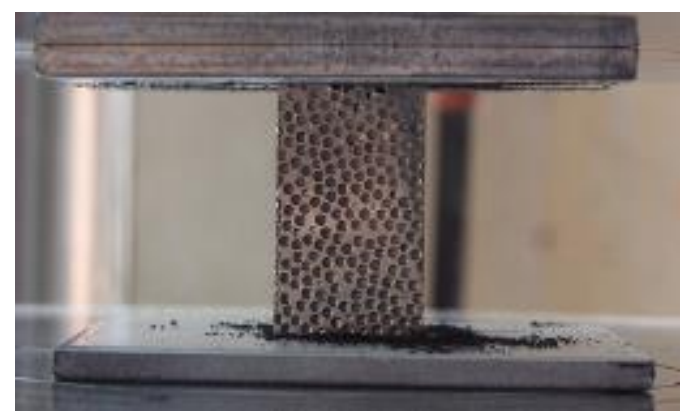

Figure 3. A metal foam under compressive loading (Source: Afsaneh Rabiei at North Carolina State University)

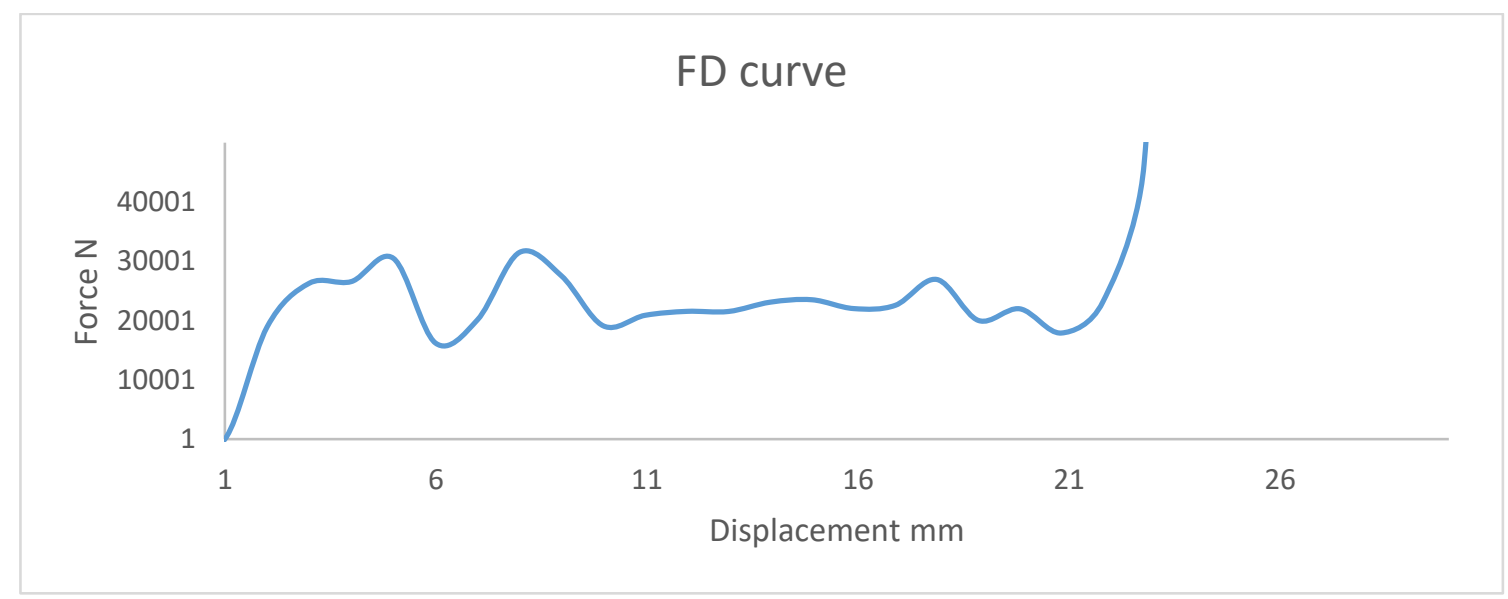

Figure 4. A typical force-displacement curve obtained from the compressive test of cellular structures 
The force-displacement curve is used to calculate the energy absorption, find the deformed length and study the failure behavior and so on. the figure bellows shows a schematic of a force-displacement curve and its various components.

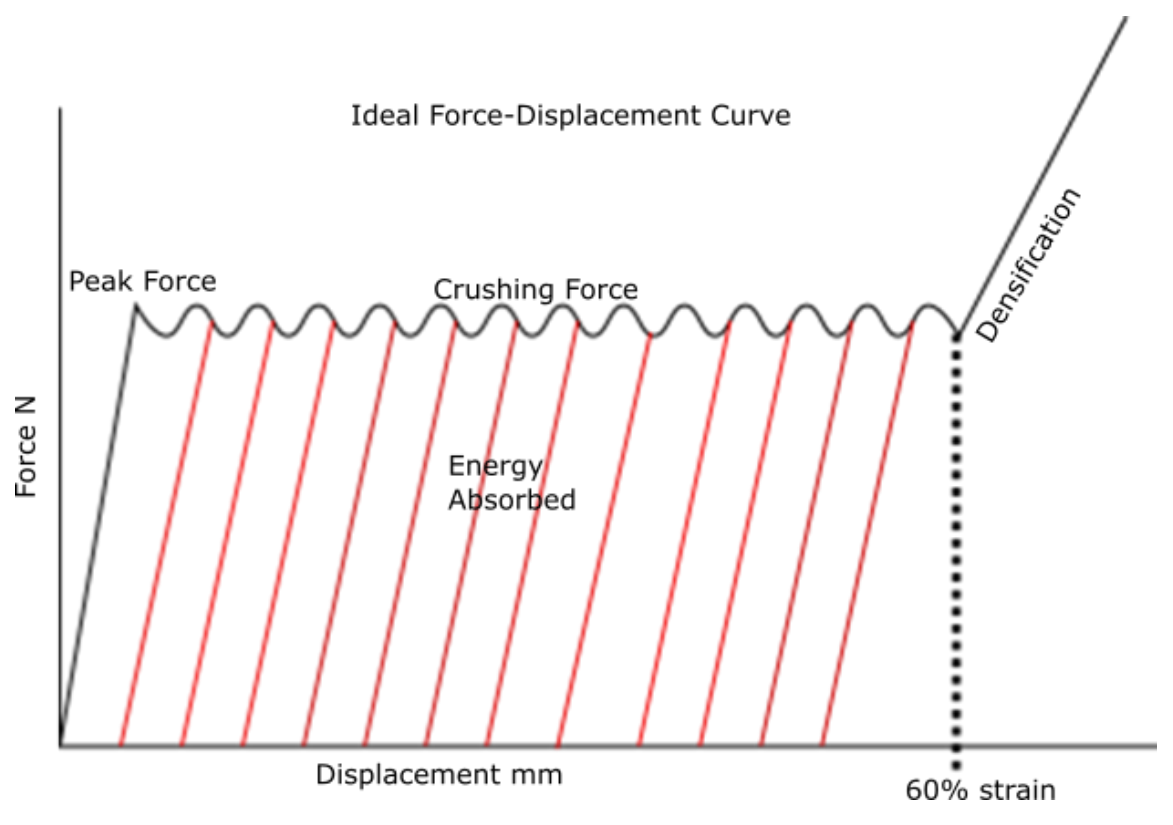

Figure 5. Ideal force-displacement curve

\section{Objectives and Scope}

The main objectives of this project are to design novel metal cellular structures using computer aided design (CAD) and simulate their behaviors using finite element analysis (FEA) software Abaqus/Explicit.

The scope of this project is clearly stated as follows:

a. The study of the cellular structures is carried out using simulation.

b. Only aluminum and titanium were considered as materials for this study.

c. Focus has been primarily on the energy absorption properties.

d. This is a purely academic endeavor.

While the scope may seem very narrow, there are reasons for them. Firstly, due to lack of a 3D-printer, it has not been possible to fabricate the designs thus restricting the project to CADs and simulations. Secondly, given the prospect of fabricating it in future, the two most commonly used materials in additive manufacturing are titanium and aluminum. Hence, they are the material of choice. Thirdly, cellular structures can also be used in many different applications such as noise isolation, heat exchangers, blast resistance, shockwave absorbers, filtration and so on. However, due to their lightweights and easy transportability, they may be used in automobiles to save fuel and perhaps save lives during collision due their energy absorbing abilities. Finally, while it has lots of potential to become a consumer product, it is currently in development and has to go through long before it becomes a matured product. Thus, commercial exploitation is not within the scope of this project. 


\section{Constraints}

The main constraints are identified within the scope of the project. Since this is project is computationally demanding, the primary constraint is the time taken to simulate the models. Other constraints include the sizes of the designs, the materials used and so on. Having large or complex designs also increase the computation time. In general, all the designs are restricted to a space of $50 \times 50 \times 50 \mathrm{~mm}^{3}$. The unit cells are constrained by $10 \times 10 \times 10 \mathrm{~mm}^{3}$. These constraints are not actual constraints but rather they are taken from research papers that generally use these dimension for their specimen. The materials are fixed such as titanium. Interestingly, money is not a constraint in this project since there was no fabrication involved. The licenses for the software used were obtained by the university.

\section{Standards and Codes}

While there are standards and codes used for testing energy absorption of cellular structure, there are no standards specified for designing them. Thus, in this project no specific standards were used to design the cellular structures. However, the general dimensions and other important parameters have been taken from typical research papers published in the field of energy absorbing cellular materials. In the future, if it becomes feasible to fabricate and test these models then surely standards should be followed.

\section{Methodology}

This senior project is a basic research in the field of cellular materials carried out using computer aided engineering (CAE) and simulations based on non-linear FEA. The advantages of using $\mathrm{CAD} / \mathrm{CAE}$ and FEA are plenty. They allow people easy, inexpensive, and iterative tests of different designs that would otherwise cost a fortune when fabricated and tested in reallife. This is a valid method of conducting primary research given that the simulation results are validated. Here is an anecdote that elaborates this technique of research. Back in the early 1900s, Einstein did not have much of the technology to validate his theory of relativity. All he had at his disposal was plenty of time and his knowledge of physics and mathematics - which were sufficient to formulate one of the most brilliant physical theories of the twentieth century. Many years later when technology finally caught up, scientists were able to experimentally confirm the validity of the theory of relativity. While this project may not be as groundbreaking as Einstein's theory was, it still adds important knowledge to the corpus of materials science. Nevertheless, it is expected that the results achieved from this project will be carried forward and experimentally confirmed in the future when such opportunity arises.

In order to show that it is possible to design cellular structures for energy absorption application, it is necessary to show that energy absorption depends on the geometry of the cellular structure. Additionally, it is necessary show that it is possible to systematically design that geometry. The UREP work showed that energy absorption is in fact affected by geometry and the three best geometries with regard to energy absorption was suggested for fabrication. While the fabrication did not actually happen due to the same restriction mentioned in the scope of this paper, the results of UREP were intriguing and fueled the initial ideas for this extension. This paper shows how the geometry can be designed in order to achieve some desired results 
such as failure behavior and energy absorption. The key findings of UREP, details of which are partially reproduced in the appendix, have been as follows:

a. Material distribution within the cellular structure affects failure behavior.

b. Even the same geometry can fail differently due to material distribution.

c. Not all designs will have buckling even if they have same geometry, depending on material distribution.

d. Some designs will bend or twist while others will not, depending on material distribution.

e. Some designs can fail progressively depending on material distribution.

f. The force-displacement curves are affected by material distribution and geometry.

Even though studying the material distribution within the cells were not the objective of UREP, the connection between material distribution within the cellular structures and their failure behavior was obvious from the results. The UREP work included an extensive simulationbased investigation to study the effects of geometry on energy absorption. When every other parameter remains constant and only the geometry is varied, it has been found that some geometries absorbed more energy than others. However, when the selected geometries were subjected different material distribution, then some designs performed better than the others even though the basic geometry was same. In short, the UREP work showed an important conclusion: both the geometry of the cellular material and the material distribution within the cellular structure affect the energy absorptions, failure behaviors and force-displacement curves.

The idea of material distribution affecting the folding mechanism has been further investigated by Resrepo et a. in their work titled "Phase transforming cellular materials" [1]. Even though their work focused on polymers, it nevertheless inspired the students to go ahead to try to design the metal cellular structures using a similar approach but not quite the same.

This conclusion leads to the hypothesis of this project. Is it possible to design cellular materials for energy absorption applications? Notice the emphasis has been on design. Since it is found out that geometry affects energy absorption and material distribution also affects energy absorption, then the last thing that remains is to design a cellular structure that combines the right geometry with the right material distribution to achieve the desired energy absorption properties. How exactly the materials are distributed? This is a challenge. As this paper will show, the greatest challenge lies in finding the right balance of material distribution within the appropriate locations of the cellular structure. And that each design is different from the others, and it has to be given its own individual treatment in order to enhance its energy absorbing properties. The following flowchart summarizes the incremental learning approach used in this project. 


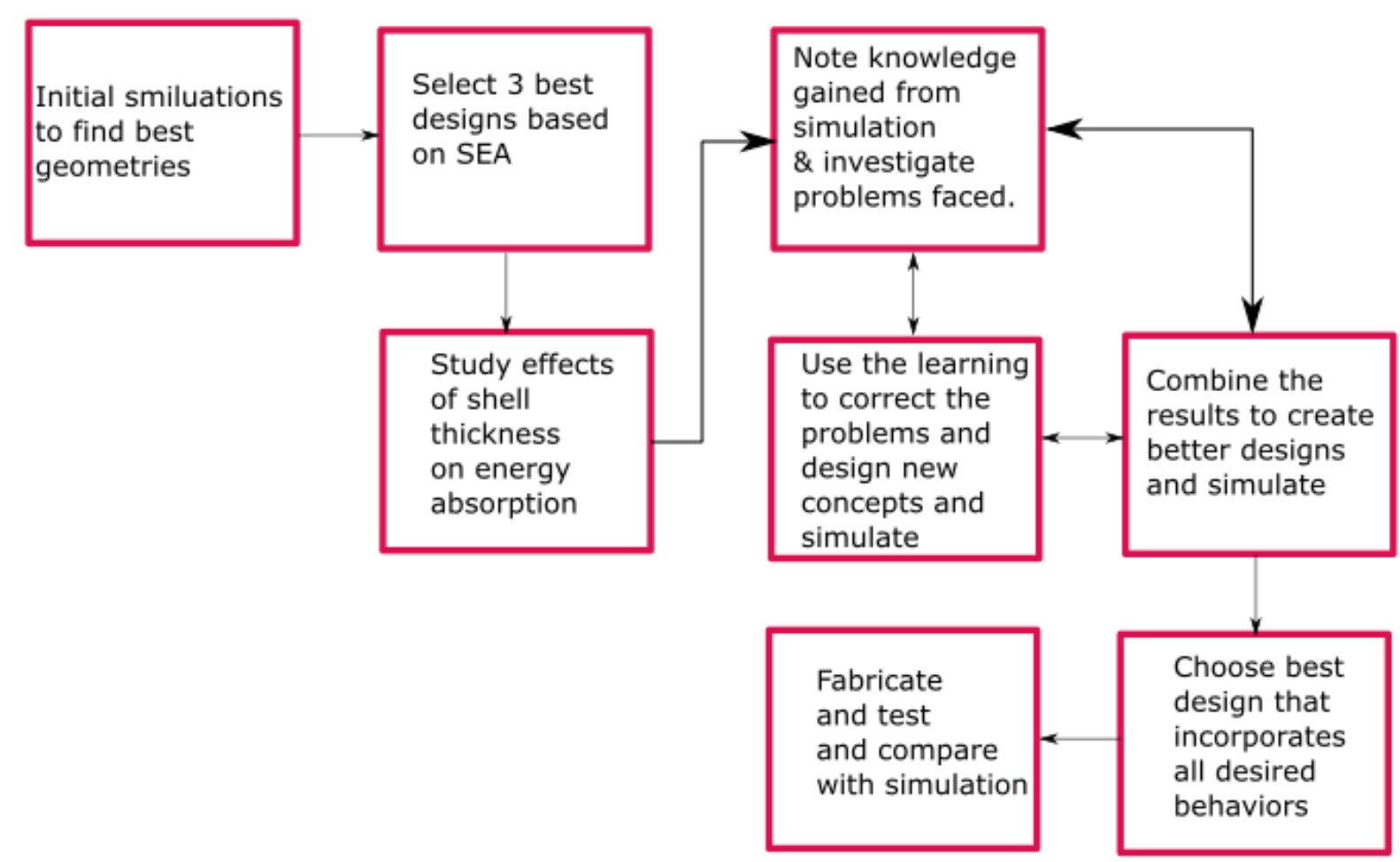

Figure 6. Incremental learning curve shown in flowchart form used for this project

\section{FEA Validation}

There are three important validations required in this project. Firstly, the validation of the FEA. Secondly, the validation of material model used for both aluminum and titanium. Thirdly, the physical validation in the form of an experiment. The following paragraphs describe these validations in detail. Since this project is entirely done on simulation, it is very important to validate the FEA model and the simulation setup. There are many things to consider in FEA validation and simulation setup including mesh sensitivity analysis, boundary conditions, applied loads, physical phenomena (such as friction, gravity, and air resistance), relevant physical laws (such as conservation laws, laws of thermodynamics, and electromagnetism) and so on. The more factors that the simulation accounts for, the better the results will be. However, this comes at the expense of the computation power and time - both of which are practical constraints. Additionally, since the simulations are based on non-linear FEA, it is important to validate the material models. It is not an easy task to analytically derive the equations of nonlinear material behavior. Researchers have carried out extensive experiments upon which they created some approximate models. The simulations are based on these approximate models and are also subjected to the restrictions posed by the data from which the model was derived.

To address the validation of the FEA, it is necessary to address the software that will run the simulation - in this case Abaqus/Explicit. Abaqus is a general purpose finite element software that is widely used by the academia to simulate computation fluid dynamics, structural mechanics, electromagnetism, linear and nonlinear behavior of structures. Designing cellular structures for energy absorption falls within the realms of non-linear finite element. The 
mathematics involved in nonlinear finite element is beyond the scope of most undergrad programs. Thus, it would be foolish to venture deep into analytical validation of non-linear FEA. Instead, the approach taken here is to use the understanding of linear FEA to grasp the basic concepts of the software, and use published papers to setup the simulation and use logical reasoning to defend the validity of this method. At the end of the day, the simulation results are only as good as they can predict the reality. The reality check would only come after experimentation. Thus, the FEA model validation is done in a step by step process following the procedures obtained from a published paper while keeping in mind the workings of the FEA software.

The first paper used for validating the FEA model setup on Abaqus is titled "Design of thin wall structures for energy absorption applications: Enhancement of crashworthiness due to axial and oblique impact forces" [2]. In this paper, the authors have clearly shown how they assembled their design, applied the boundary conditions, required forced and so on. This paper has been replicated and the same results were obtained thus ensuring that the students can repeat this paper. After that, all the parameters were fixed and only the geometry were changed. The reasoning is that if everything else remains same and only the geometry is varied, then the change in the results can be attributed to the different geometry. However, it should be kept in mind that with the change of the geometry the choice of the appropriate mesh also come into play. Thus, a mesh sensitivity analysis has been performed to validate the mesh size that has been explained in a later paragraph. The paper also utilized a multi-criteria decision making process to evaluate the best design. In this paper, a simpler qualitative approach based on numerical and visual techniques will be used to compare the designs.

The Figure 7 shows the assembly of the cellular structure. The assembly consists of three main parts namely the top plate, the cellular structure and the bottom plate. The top plate is called the striker. An inertial mass $(250 \mathrm{~kg})$ is assigned to the striker and it also crashes down upon the cellular structure with a given velocity $(13.9 \mathrm{~m} / \mathrm{s})$. The bottom plate is called the base and it is fixed. There is a constraint between the cellular structure and the base such that they are tied to each other and remain in contact throughout the simulation. A friction coefficient of 0.2 is applied for the entire model. The type of analysis performed is dynamic-explicit. The crash time is 0.005 seconds with 200 intervals for data points. The material properties are based on the Johnson-Cook model, which is also validated research papers. The mesh of the striker and the base are coarse since they do not affect the energy absorption results. In Abaqus/Explicit, the top and bottom plates are modeled as 3D, rigid body, shell-plates. The cellular structure is modeled as 3D, deformable, shell-extrusion. The cellular structure occupies a geometric volume of $50 \times 50 \times 50 \mathrm{~mm}^{3}$. Although longer lengths such as $100 \mathrm{~mm}$ and $200 \mathrm{~mm}$ were simulated for many designs, the main focus was on the $50 \mathrm{~mm}$ design. The designs start by first drawing the unit cell which is a $10 \times 10 \times 10 \mathrm{~mm}^{3}$ shape and then replicating it to fill the larger matrices. The kinetic energy obtained for this setup is $250 \times 13.9^{2} \times 0.5=24151.25 \mathrm{~J}$. Thus, the energy absorption of the cellular structure must not be equal to more than $24 \mathrm{~kJ}$. 


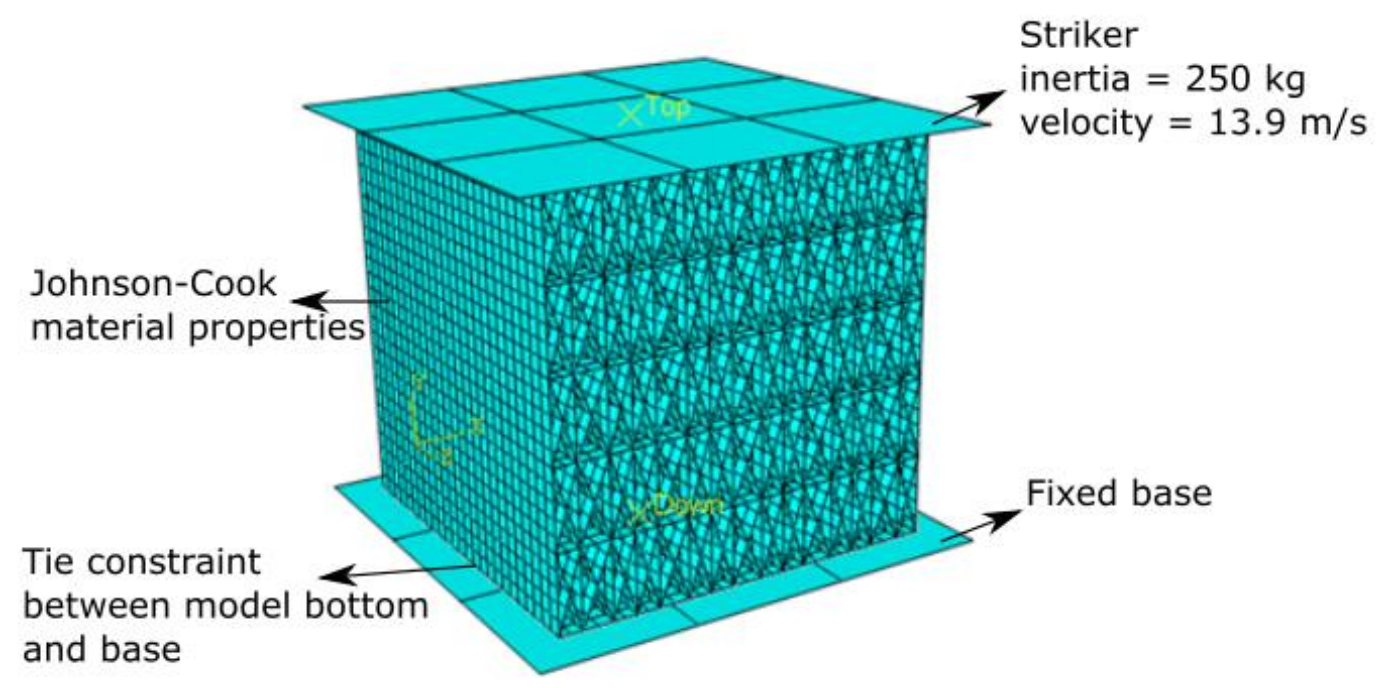

Figure 7. The assembly of a cellular structure

The Table 1 below lists the Johnson-Cook properties for aluminum and titanium that is used in the simulations. Abaqus has its own set of units as shown in Figure 8. Thus it is necessary to follow the unit convention it uses as mentioned in the user guide. The density distribution is uniform. The elastic behavior is isotropic. The plastic hardening is defined by rate dependent Johnson-Cook model. Initially, the simulations were run using fixed stress-strain data obtained for both aluminum and titanium. However, do to the nonlinear nature of the simulation and the high strain these materials go through under these impact simulations, Johnson-Cook model was suggested as a better alternative by "Experimental investigation of plastic deformation of Ti-6Al-4V under various loading conditions." It is to be noted that the Johnson-Cook model considers the thermal effects on stresses and strains of the material. While Abaqus does account of the thermal parameters in the Johnson-Cook model, the thermal behavior itself is not a major concern due to the nature of the impact. The Johnson-Cook values for titanium were obtained from "Validation of Johnson-Cook plasticity and damage model using impact experiment" [3] and as well as "Experimental investigation of plastic deformation of Ti-6Al-4V under various loading conditions" [4]. The Johnson-Cook values for aluminum were obtained from "Variable strain rate sensitivity in an aluminium alloy: Response and constitutive modeling" [5] and the online material database MatWeb [6].

Table 1. Johnson-Cook parameters for aluminum and titanium

\begin{tabular}{llll}
\hline Parameter & Aluminum Values & Titanium Values & Description \\
\hline A $[\mathrm{MPa}]$ & 275.9767 & 1055 & Material parameter \\
$\mathrm{B}[\mathrm{MPa}]$ & 700.43 & 426 & Material parameter \\
$\mathrm{N}$ & 0.4208 & 0.5035 & $\begin{array}{l}\text { Strain power } \\
\text { coefficient }\end{array}$ \\
$\mathrm{C}$ & 0.0001726 & 0.023 & Material parameter \\
$\mathrm{M}$ & 1.368 & 0.8 & Temperature power \\
& & & coefficient \\
$\dot{\epsilon_{0}\left[S^{-1}\right]}$ & 1 & 1 & Reference strain rate \\
\hline
\end{tabular}




\begin{tabular}{llll}
\hline$\rho\left[\mathrm{kg} / \mathrm{m}^{3}\right]$ & 2780 & 4430 & Density \\
$\mathrm{Tm}\left[{ }^{\circ} \mathrm{C}\right]$ & 502 & 1600 & Melting temperature \\
$\mathrm{Tt}\left[{ }^{\circ} \mathrm{C}\right]$ & 413 & 982 & Transition temperature \\
$\mathrm{E}[\mathrm{MPa}]$ & 73100 & 104800 & Young's modulus \\
$v$ & 0.33 & 0.31 & Poisson's ratio \\
\hline
\end{tabular}

\begin{tabular}{|c|c|c|c|c|}
\hline Quantity & SI & SI (mm) & US Unit (ft) & US Unit (inch) \\
\hline Length & $\mathrm{m}$ & $\mathrm{mm}$ & $\mathrm{ft}$ & in \\
\hline Force & $\mathrm{N}$ & $\mathrm{N}$ & $\mathrm{lbf}$ & $\mathrm{lbf}$ \\
\hline Mass & $\mathrm{kg}$ & tonne $\left(10^{3} \mathrm{~kg}\right)$ & slug & $\mathrm{lbf} \mathrm{s}^{2} / \mathrm{in}$ \\
\hline Time & $\mathrm{s}$ & $\mathrm{s}$ & $\mathrm{s}$ & $\mathrm{s}$ \\
\hline Stress & $\mathrm{Pa}\left(\mathrm{N} / \mathrm{m}^{2}\right)$ & $\mathrm{MPa}\left(\mathrm{N} / \mathrm{mm}^{2}\right)$ & $\mathrm{lbf} / \mathrm{ft}^{2}$ & $\mathrm{psi}\left(\mathrm{lbf} / \mathrm{in}^{2}\right)$ \\
\hline Energy & $\mathrm{J}$ & $\mathrm{mJ}\left(10^{-3} \mathrm{~J}\right)$ & $\mathrm{ft} \mathrm{lbf}$ & in $\mathrm{lbf}$ \\
\hline Density & $\mathrm{kg} / \mathrm{m}^{3}$ & tonne $/ \mathrm{mm}^{3}$ & slug/ $/ \mathrm{ft}^{3}$ & lbf $s^{2} / \mathrm{in}^{4}$ \\
\hline
\end{tabular}

Figure 8. ABAQUS unit system (Source: ABAQUS Explicit 6.14 User Manual)

In the above passages, the FEA model setup and the materials properties have been validated using different research papers. In this part, the mesh sensitivity analysis will be discussed. More clearly, the effects of changing mesh sizes on the energy absorption will be discussed. The following Figure 9 show the mesh size and the time taken to simulate the FEA model. It shows that as the mesh size becomes finer the more time it takes to simulate it. While as the mesh gets coarse the time reduces significantly and often does not make a big different between different coarse meshes as indicated by the vertical section of the curve. The curve can also be represented in terms of number of elements vs the time taken as shown in the next Figure 10. 


\section{Mesh Size vs Time}

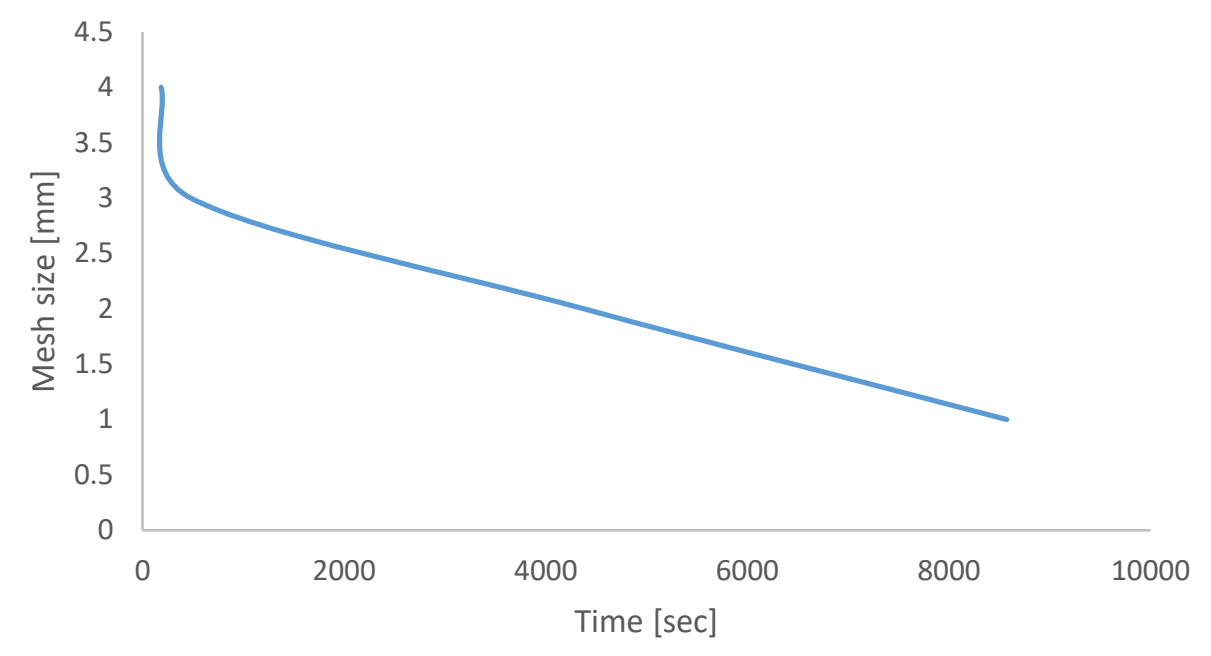

Figure 9. Mesh size vs time taken for simulations

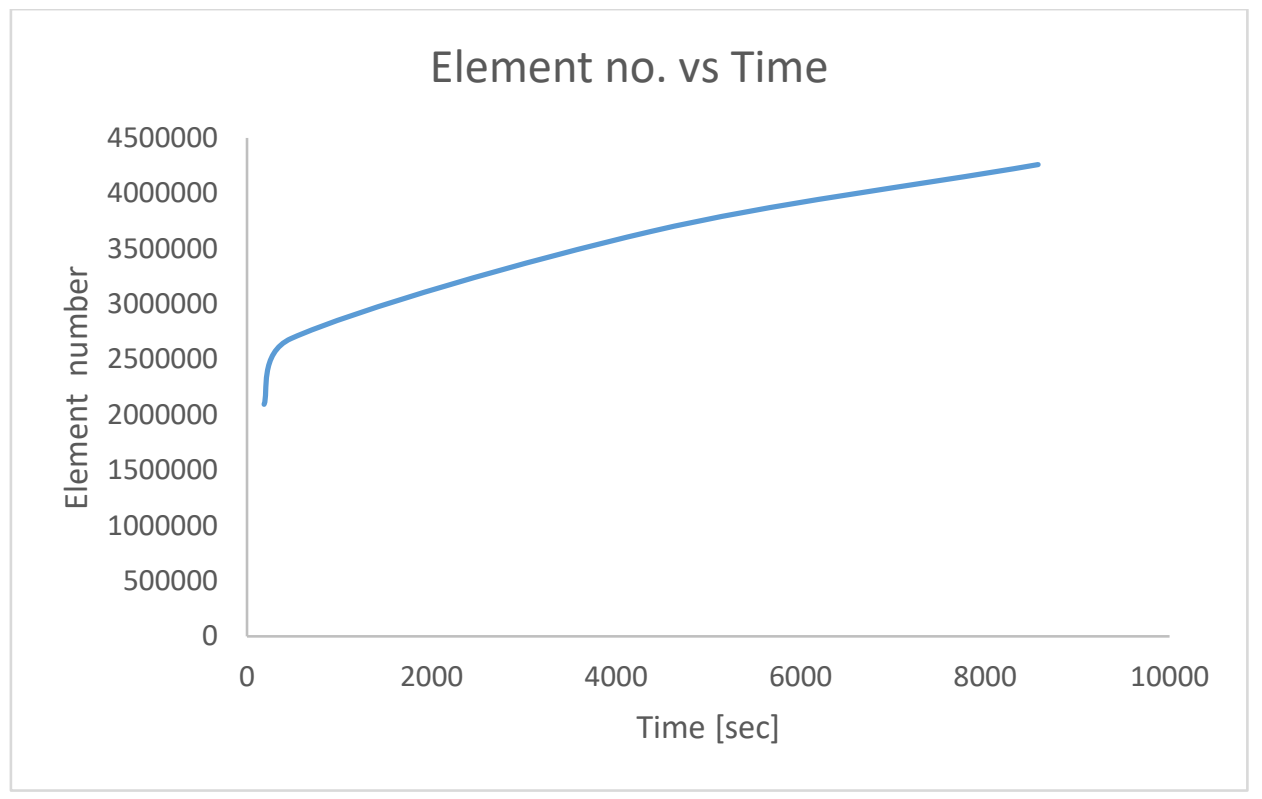

Figure 10. Number of elements vs time taken for simulation

However, the issue of the appropriate mesh size is not limited to the time but also to the accuracy of the result. It is found from this mesh sensitivity analysis that the difference between the largest and the smallest energy absorption values was $1420 \mathrm{~J}$ or $1.42 \mathrm{~kJ} .1 .42 \mathrm{~kJ}$ out of 24 $\mathrm{kJ}$ is about 6\%. A $6 \%$ percent error maybe acceptable given that it still provides a good approximation for the simulation. Based on this mesh sensitivity analysis, it was decided to use a mesh size of $1 \mathrm{~mm}$ for the simulations. Additionally, quad elements were chosen based on the research paper. The choice for type of element is also important as some give better results than others. Again this comes at the cost of computation times. The correct element type can be identified by using mesh sensitivity analysis as shown in the above figures. However, this was not carried out due to lack of time and quad was chosen to be the default. 


\section{Simulations, Results and Discussions}

Many designs have been simulated all having constant parameters as shown in the figure below. the objective of these initial simulations is to compare the effects of geometry on the energy absorption. This was ensured by having all other parameters constant.

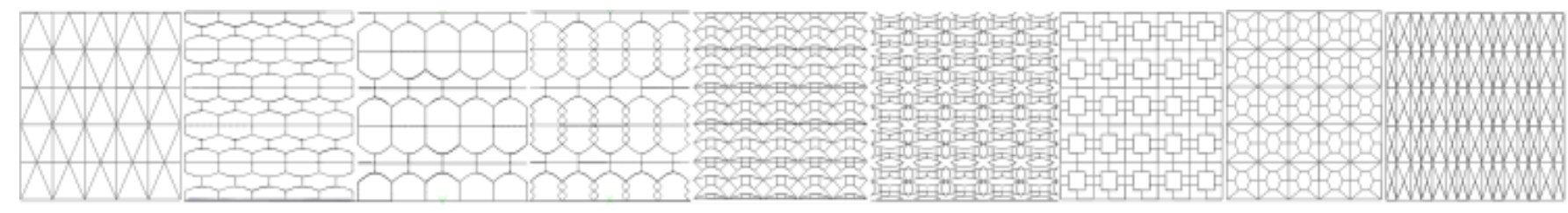

Figure 11. Sample designs that have been used to find the good geometries for energy absorption

From these designs, only the best three designs have been selected based on specific energy absorption for further investigations as shown below. Once the effect of geometry of the energy absorption is confirmed, the second round of simulations were meant to study what component within a given geometry affects the energy absorption.

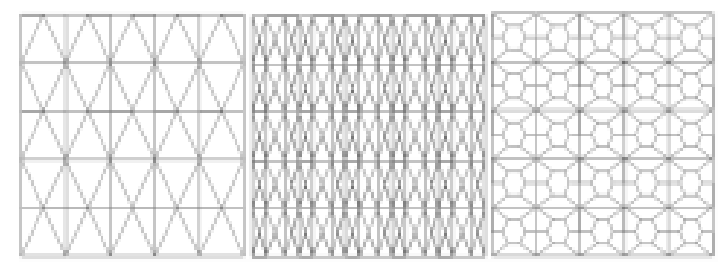

Figure 12. The selected best three designs based on specific energy absorption

The thickness of the shells has been chosen as a key variable for studying energy absorption. Then, the designs were assigned two different thicknesses - one on the walls and the other on the struts as shown below. A factorial experimental method was used for this purpose. Using a low thickness of $0.5 \mathrm{~mm}$ and a high thickness of $1.25 \mathrm{~mm}$, four combinations were made from each design. 


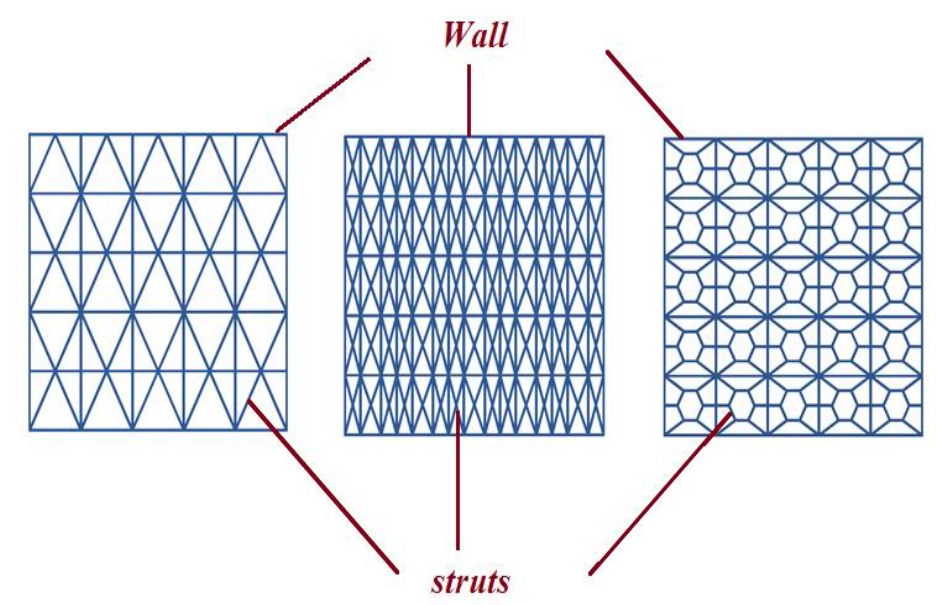

Figure 13. The thicknesses were modified in the walls and the struts

Next, 50mm, 100mm, 200mm lengths were chosen along with two materials -aluminum and titanium - to carry out the simulations.

Table 2. Tables shows the matrix of the combinations used for materials, lengths and thickness totaling 72

\begin{tabular}{|c|c|c|c|}
\hline Designs & (N) & \begin{tabular}{|} 
1. \\
1 \\
1
\end{tabular} & 级争象 \\
\hline $\begin{array}{l}\text { Shell Thickness } \\
\text { Combinations } \\
{[\mathrm{mm}]}\end{array}$ & $\begin{array}{l}\text { Wall-0.5 Strut-0.5 } \\
\text { Wall-0.5 Strut- } 1.25 \\
\text { Wall-1.25 Strut-1.25 } \\
\text { Wall-1.25 Strut-0.5 }\end{array}$ & $\begin{array}{l}\text { Wall-0.5 Strut- } 0.5 \\
\text { Wall-0.5 Strut- } 1.25 \\
\text { Wall-1.25 Strut-1.25 } \\
\text { Wall-1.25 Strut-0.5 }\end{array}$ & $\begin{array}{l}\text { Wall-0.5 Strut-0.5 } \\
\text { Wall-0.5 Strut- } 1.25 \\
\text { Wall-1.25 Strut-1.25 } \\
\text { Wall-1.25 Strut-0.5 }\end{array}$ \\
\hline Lengths $[\mathrm{mm}]$ & $50,100,200$ & $50,100,200$ & $50,100,200$ \\
\hline Volume [mm^3] & $\begin{array}{l}50 \times 50 \times 50 \\
50 \times 50 \times 100 \\
50 \times 50 \times 200\end{array}$ & $\begin{array}{l}50 \times 50 \times 50 \\
50 \times 50 \times 100 \\
50 \times 50 \times 200\end{array}$ & $\begin{array}{l}50 \times 50 \times 50 \\
50 \times 50 \times 100 \\
50 \times 50 \times 200\end{array}$ \\
\hline Materials & Aluminum, titanium & Aluminum, titanium & Aluminum, titanium \\
\hline $\begin{array}{l}\text { Simulations per } \\
\text { design }\end{array}$ & $4 \times 3 \times 2=24$ & $4 \times 3 \times 2=24$ & $4 \times 3 \times 2=24$ \\
\hline Total simulations & \multicolumn{3}{|c|}{72} \\
\hline
\end{tabular}

Much important knowledge was gained from these simulations. They showed that the thicknesses affect the energy absorption as well as the failure behavior of the cellular structures. In general, the $200 \mathrm{~mm}$ designs showed most buckling behaviors while the $50 \mathrm{~mm}$ showed least. Some designs showed progressive failure while others were random or uniformly in all cell 
layers simultaneously. Most of the designs also have high peak force in the ranges of $600 \mathrm{kN}$ and above. The strain rate was very low - much lower than $60 \%$. The force displacement curves were all shooting up very high and very fast. Even though all these problems seemed to be disappointing at first sight, it eventually helped to form the next round of simulations and the ultimate hypothesis for this project. Using the learnings from these individual simulations, could it be possible to design cellular materials that can have $60 \%$ strain rate, collapse progressively, have lower peak forces and more stable crush force all at the same time? It was a brave hypothesis. Nevertheless, it had been decided to tackle each of these problems one at a time as shown in the table below. it has been an incremental learning combined with tackling the problems cumulatively. Obviously, the table itself cannot be understood very clearly unless the force-displacement curve is presented along with it. However, to keep the report concise and to the point, the graphs have been omitted but the general findings have been combined in one figure as shown in Figure 13. From the table 3, it can be noted that most of the problems found in the earlier simulations have been corrected using an incremental-improvement approach based on knowledge gained from each iterations. The final challenge was to incorporate all these results together to create at least one design that proves the hypothesis. As shown in the following pages, this have been achieved and with remarkable conclusions. 
Table 3. Table shows how the problems were broken down and corrected using incremental learning

\begin{tabular}{|c|c|c|c|}
\hline Key Problems & Investigations & Corrective Modifications & Results \\
\hline High peak forces & $\begin{array}{l}\text { Understand how shell thickness can } \\
\text { affect peak forces. Is it too rigid or } \\
\text { stiff? }\end{array}$ & $\begin{array}{l}\text { Having too rigid or stiff designs can lead to high } \\
\text { forces. The geometries can be made more } \\
\text { flexible by reducing overall shell thicknesses } \\
\text { such that the design can start folding easily } \\
\text { upon impact. }\end{array}$ & $\begin{array}{l}\text { Reduced peak forces from } \\
600 \mathrm{kN} \text { to } 30 \mathrm{kN} \text {. It is } \\
\text { interesting how material } \\
\text { distribution in the shells can } \\
\text { affect peak forces. }\end{array}$ \\
\hline $\begin{array}{l}\text { Unstable crushing } \\
\text { forces }\end{array}$ & $\begin{array}{l}\text { Why are forces in the crushing region } \\
\text { constantly rising up and quite fast? } \\
\text { Maybe the design is dense such that it } \\
\text { starts densifying quite early? }\end{array}$ & $\begin{array}{l}\text { To stabilize the crush force, the upper regions } \\
\text { of the cellular structures were assigned a thinner } \\
\text { shell thickness compared to the lower regions. } \\
\text { This would allow more spaces for the cellular } \\
\text { structure to collapse without being to crammed } \\
\text { at least in the top region. However, having } \\
\text { thinner shell sections in the lower region could } \\
\text { lead to premature buckling or bending. }\end{array}$ & $\begin{array}{l}\text { Consequently, crush forces } \\
\text { began to stabilize. The } \\
\text { constantly rising slope that } \\
\text { was seen previously has now } \\
\text { started being more horizontal. } \\
\text { That is a good improvement! }\end{array}$ \\
\hline $\begin{array}{l}\text { Sharp peaks in } \\
\text { crushing phase }\end{array}$ & $\begin{array}{l}\text { Why are these sharp peaks occurring in } \\
\text { the crush force region? Can they be } \\
\text { related to the geometry or material } \\
\text { distribution? By counting the number } \\
\text { of the peaks, it was observed that the } \\
\text { number of peaks were corresponding to } \\
\text { the number of layers in the cellular } \\
\text { structure. Perhaps each layer gave rise } \\
\text { to a new peak? The distance between } \\
\text { the peaks were about } 8 \text { to } 10 \mathrm{~mm} \text {. This } \\
\text { was an interesting finding. Why were } \\
\text { the layers causing the peaks? }\end{array}$ & $\begin{array}{l}\text { The main idea to reduce the peaks in the } \\
\text { crushing force region was to create a damping } \\
\text { effect within the cellular structure. This was } \\
\text { achieved by making the horizontal struts for the } \\
\text { layers thicker than the rest. }\end{array}$ & $\begin{array}{l}\text { Obviously, the peaks damped } \\
\text { and became smoother. }\end{array}$ \\
\hline $\begin{array}{l}\text { Less than } 60 \% \\
\text { strain rate }\end{array}$ & $\begin{array}{l}\text { What causes early densification? Can } \\
\text { the strain rate be extended? }\end{array}$ & $\begin{array}{l}\text { Densification starts when the cellular structure } \\
\text { cannot collapse anymore without the top } \\
\text { materials touching the bottom material and } \\
\text { pushing them. This occurs as there is no more }\end{array}$ & $\begin{array}{l}\text { Of course, what eventually } \\
\text { occurred is that the strain rate } \\
\text { kept increasing with each }\end{array}$ \\
\hline
\end{tabular}


space left for folding. So, the cellular structures were assigned shell thickness such that the vertical struts could easily collapse.

Buckling and nonprogressive folding

\section{Spring-like} rebounding effect

Cellular structure bulges out
Buckling is usually observed in beam structures. Correcting buckling maybe a challenge? Maybe study the modes of the design? Can material distribution help with reducing it? The remedy for buckling is having a progressive collapse. It is like killing two birds with one stone.

The cellular structure seems to jump like a spring. This leads to negative values in the force-displacement curves. How to prevent it?

Instead of folding inwards, the cellular material bulges outwards as it goes down. It maybe be a problem for tight spaces. How to make the folding confined within?
Instead of focusing on preventing buckling, the effort has been made to achieve progressive collapse. The reasoning was that by having progressive collapse, the buckling could be automatically prevented. Thus, shell thicknesses were assigned intelligently around the various struts to ensure it fails progressively top to bottom.

Due to material elasticity, sometimes the cellular structures were behaving as spring since the force caused them to store strain energy which was released instantaneously. To prevent this behavior, the geometry of the designs was altered such that it can fold instead of rebound like spring. Mostly this was observed where wave-like struts were present. This was eliminated by using straight struts instead of curved ones. Also thicker struts reduced this effect well.

To prevent this behavior, the struts were designed to fold inwards. For example, scissors would fold in easier than a rectangle. Thus, some struts were modified to make them more foldable by having angles or corners. trials until $60 \%$ strain rate was achieved.

As a result, progressive collapse was achieved while buckling was prevented simultaneously at least in one $100 \mathrm{~mm}$ design and almost all $50 \mathrm{~mm}$ designs.

The spring-like effect was not generally observed in many designs. However, it was controlled by making struts thicker and alternative choosing linear struts over curved ones. This removed the negative peaks from forcedisplacement curve.

The cellular structures keeps folding inwards until it densifies at which point it may bulge out a little. But generally, the bulging out was prevent by the design modifications. 
If the entire project could be captured in one image, then Figure 14 would be that image. As shown in the figure 10 below, the initial simulations showed extremely high peak forces and low strain rates. The magnitudes of these forces were in the order of $700 \mathrm{kN}$. This is not the typical behavior that is observed in traditional metal foams. Thus, there were attempts to bring down the peak forces by altering the geometry and material distribution within the cells. These design iterations and learning gained from them allowed the students to create designs intelligently such that the peak forces were reduced in subsequent iterations. Additionally, the low strain rates that marked almost all the initial samples began to lengthen until $60 \%$ strain rate was achieved. Furthermore, the average crushing force were not stable. The indigo curve shows a low peak force and unstably low crush forces. The green curve shows still a low peak force and relatively more stable crush force. But the strain rate is not perfectly $60 \%$. The blue curve shows high peak force, unstably high crush force and low strain rate. Finally, the red line shows a typical peak force, with almost stable crush force and a $60 \%$ strain rate. This design can be further developed in future. It is to be noted that the same design which created the blue curve has been improved upon to yield the red curve. This proves the hypothesis that geometry affect energy absorption and that material distribution also affects that energy absorption and failure behavior.

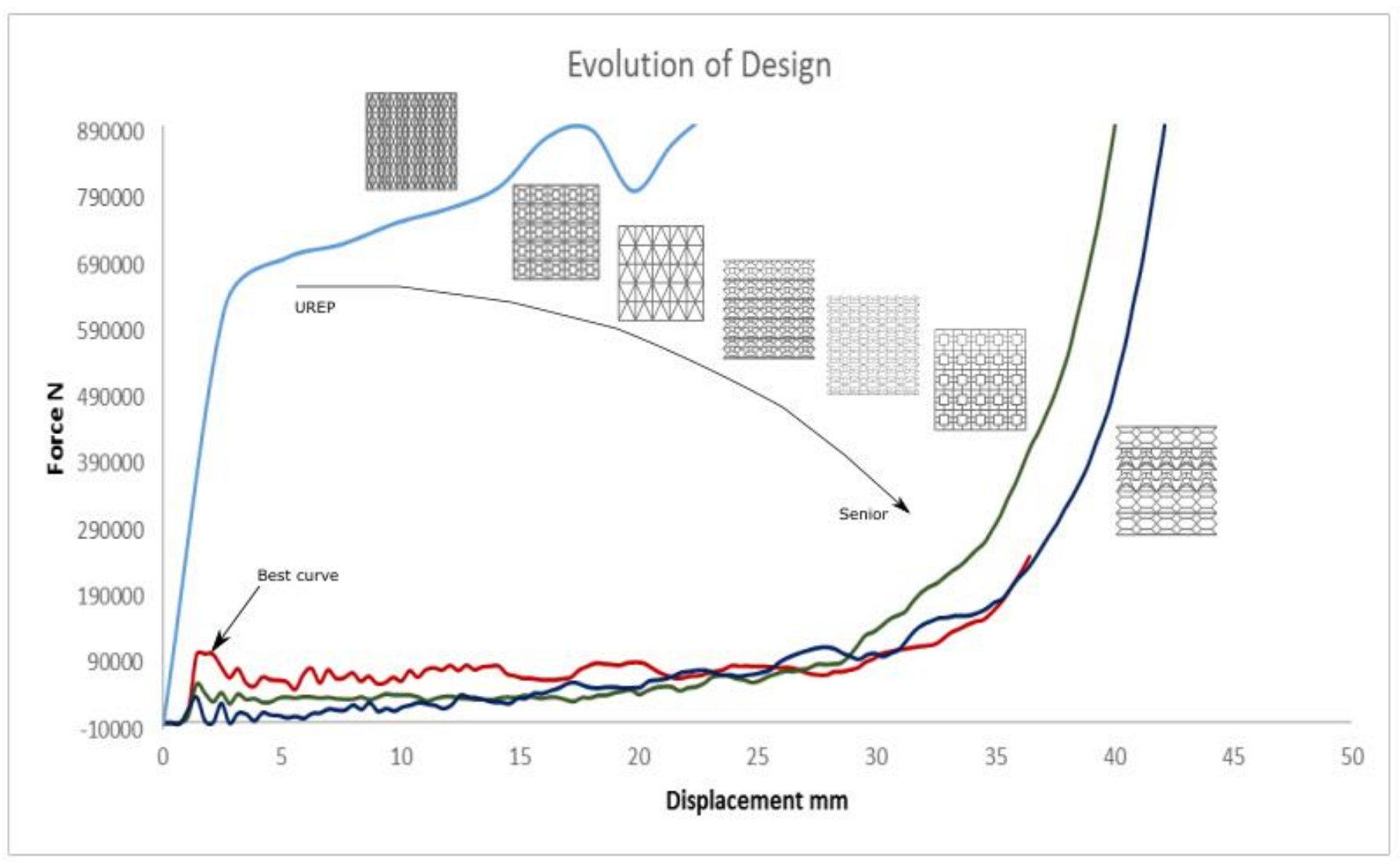

Figure 14. Evolution of cellular structure designs from UREP to senior 
The Figure 11 below shows how the materials are assigned within the shells. Notice that this is not randomly done but rather it is based on the findings listed in table 3 . While it has been a tedious process, the learning process and the results obtained have been very rewarding. The reader is reminded that this method of assigning shell thickness is very unique and individual to the design itself. A 50mm design would cannot be extended to $100 \mathrm{~mm}$ even if they share the same geometry. Rather, based on the length and geometry each one has to be designed individually. Such customizations and iterative simulations are possible because of sing finite element analysis. And in fact this is the trend set by the additive manufacturing - to be able to customize precise to suit the needs of the users.
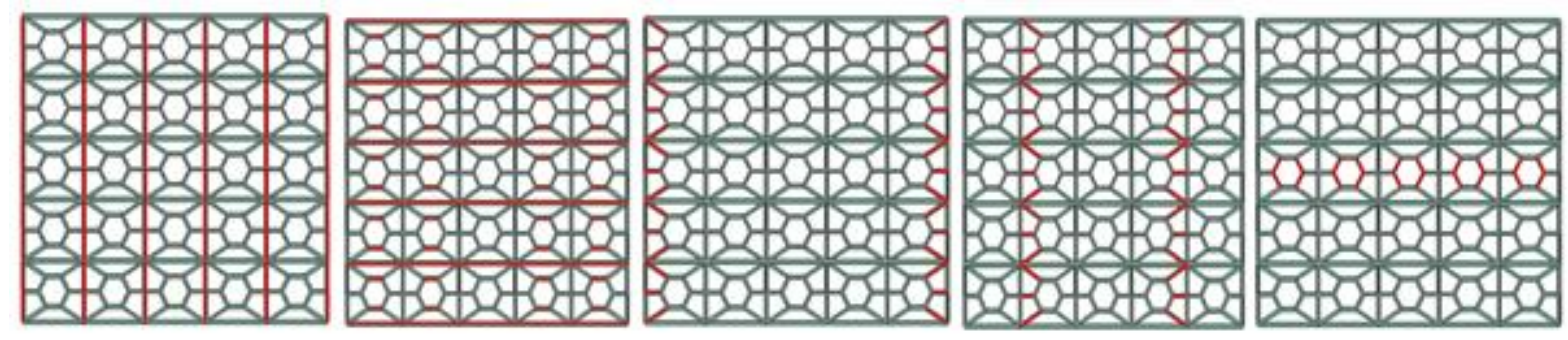

Figure 15. The tedious process of assigning the materials throughout the cellular structures

Figure 15 and Table 4 shows the thicknesses of the shells in the struts and the walls of a unit cell. The findings from Table 3 have been incorporated in this design. For example, there is no curved struts to prevent spring-like rebound effects. The horizontal struts (see struts a, b, m, f) are very thick to act as dampers and reduce the peaks in the crushing force region. The struts are designed with angles to have folding behavior instead of bulging outwards. Additional reinforcements have been used in the form of struts (see struts $d$ and k connected to g-r and hq) to prevent buckling in the long vertical struts. Progressive top-middle-bottom collapse has been achieved by using variable shell thicknesses through the geometry as shown in Table 4.

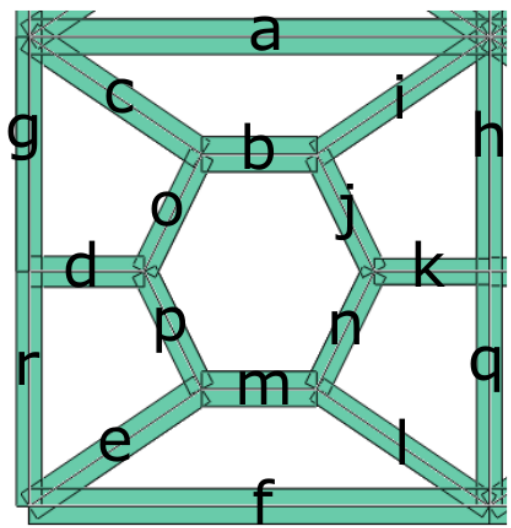

Figure 16. Different thicknesses in the shells -truly engineered for application. 
Table 4. Section thicknesses shown in Figure 15. This varies from one design to another according to the geometry. The thickness unit is in [mm].

\begin{tabular}{llll}
\hline Element & Thickness & Element & Thickness \\
\hline $\mathrm{a}$ & 1.8 & $\mathrm{j}$ & 0.35 \\
$\mathrm{~b}$ & 1.75 & $\mathrm{k}$ & 0.4 \\
$\mathrm{c}$ & 0.50 & 1 & 0.4 \\
$\mathrm{~d}$ & 0.50 & $\mathrm{~m}$ & 1.75 \\
$\mathrm{e}$ & 0.50 & $\mathrm{n}$ & 0.35 \\
$\mathrm{f}$ & 1.2 & $\mathrm{o}$ & 0.35 \\
$\mathrm{~g}$ & 0.6 & $\mathrm{p}$ & 0.35 \\
$\mathrm{~h}$ & 0.55 & $\mathrm{q}$ & 0.55 \\
$\mathrm{i}$ & 0.4 & $\mathrm{r}$ & 0.6 \\
\hline
\end{tabular}

Figure 16 reiterates the point made in the earlier paragraph. The unit cell in each location 1, 2, and 3 have different shell assignments. This is all manually configured for each design and size. It can become more complex and difficult when the sizes get longer. However, this can be addressed in the future work - to make it easier to design the cellular structures. Perhaps it may be automated if someday an algorithm can be developed that can learn by itself- as in artificial intelligence. Using its many intelligent capabilities, it may be possible to come up with designs that have ideal behaviors desired from metal cellular structures!

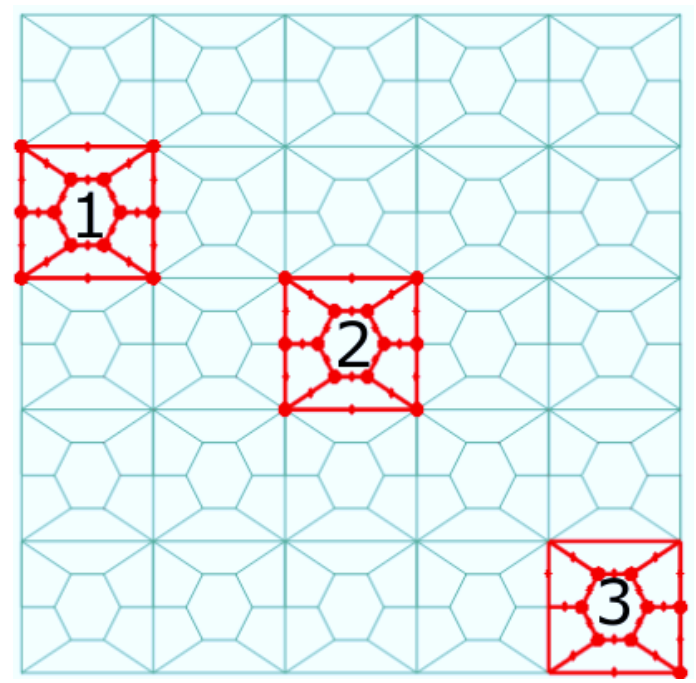

Figure 17. Different sections within the cellular structure have different shell thickness. It is truly customized.

Lastly, Figure 17 shows the force-displacement curve obtained from the final design. It has $60 \%$ strain rate, with quite stable crushing force. The peaks in the crushing force region has been smoothed out for aluminum while it is still a bit high for titanium. The peak forces have been reduced from $600 \sim 700 \mathrm{kN}$ to $70 \sim 200 \mathrm{kN}$ and as shown earlier it can be brought down much lower. The reason titanium has higher forces than aluminum can be attributed to the stiffness of the titanium. In Figure 18, the simulation of the crushing is shown. Note that it is progressive and does not have any buckling or bending. 


\section{Titanium and Aluminum}

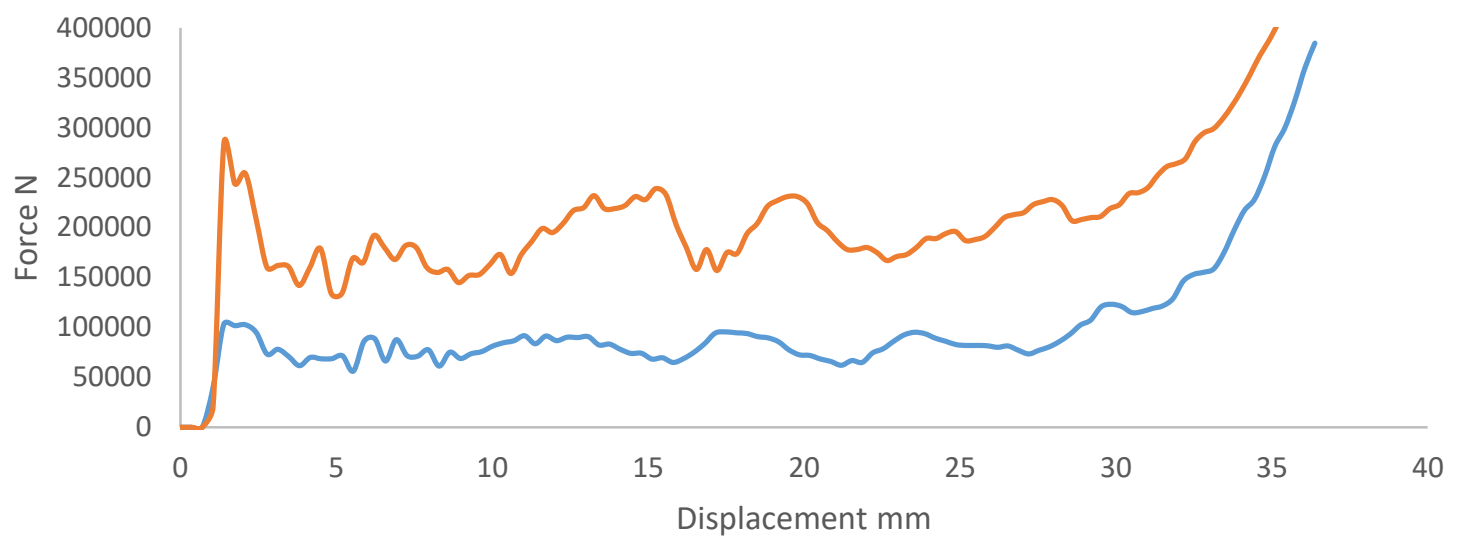

Figure 18. The same design produced a similar force-displacement curve even for different materials indicating it is the geometry that is responsible for this behavior

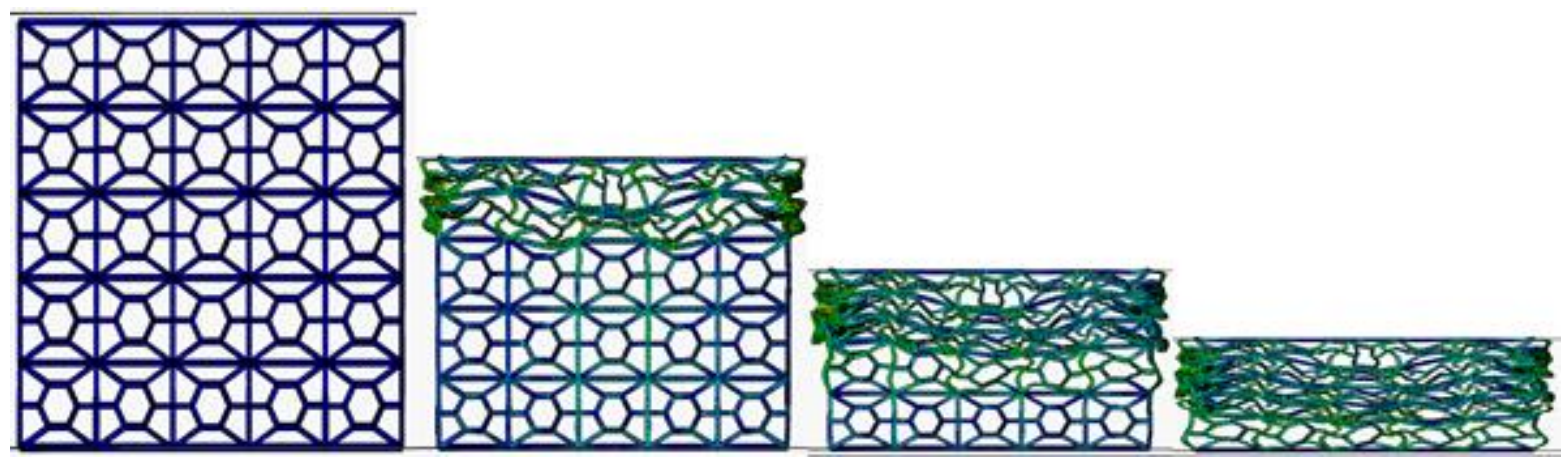

Figure 19. Progressive collapse of the final design that also produced the curves in Figure 17

\section{Future Work}

The general direction for anyone willing to take this work further are outlined below:

a. Fabricate the selected model using additive manufacturing (direct laser metal sintering or similar) preferably using aluminum or titanium

b. Use ASTM standards for running compression tests on the cellular structure

c. Plot the force-displacement curves and qualitatively compare with the ones obtained from the simulation

d. Find the specific energy absorption, crush force, peak for and so on and compare them with the simulation results

e. Discuss any discrepancies between the simulation results and the experimental work

Figure 19 shows the three selected designs in 3D model drawn using SolidWorks and exported in STL format. These can be used to fabricate the sample in 3D printer and tested using 
compressive test machine. The force-displacement curve can be generated using sensors connected to the computer and compared with the simulations results. Additionally, high resolution camera can be used to capture the deformation mechanism of the cellular structures and compared with the progressive collapse obtained in the simulation.

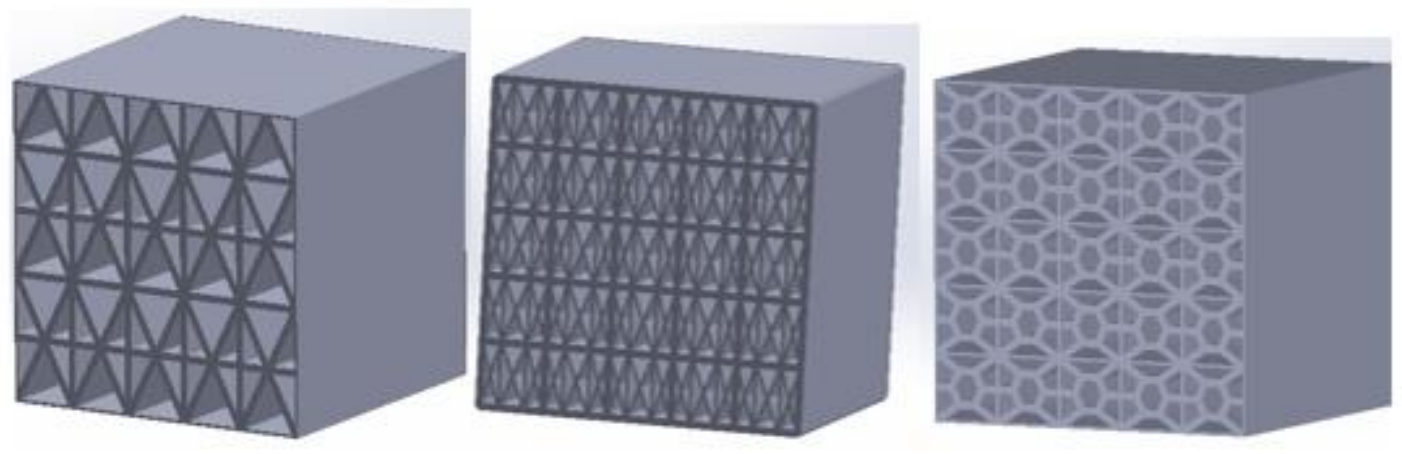

Figure 20. STL files for the samples created using SolidWorks

\section{Conclusion}

In conclusion, metal cellular materials have been used as energy absorbers for many years. With the popularity of additive printing, it is now possible to fabricate cellular structures using this technology. CAD/CAE can be used to come up with interesting and unique designs. FEA can help the users to simulate the folding behavior of the cellular structure and corresponding energy absorption for each design. It was shown through UREP work that geometry affects the energy absorption in addition to the thicknesses of the shells. A summary of UREP has been added in the appendix to show how the geometries were selected and studied. Extending from that, it is shown in this project that material distribution in the shells is a key element in designing the cellular structures that affect both the energy absorption and the folding mechanism. And that each of the designs needs to be customized and treated individually to achieve the desired results. Thus, both the geometry and the material distribution within the struts are important factors in maximizing energy absorption. Thereafter, the primary hypothesis of this senior project has been shown to be true. That means, it is possible to design cellular structures that can have good energy absorption properties. The force-displacement curve obtained was similar to the ideal one with $60 \%$ strain rate and stable crushing force. There is still room for much improvement. The same failure behavior was observed for both the titanium and the aluminum. The specific energy absorption for aluminum was found to be $18 \mathrm{~kJ} / \mathrm{kg}$ while for the titanium it was found to be $23 \mathrm{~kJ} / \mathrm{kg}$. The crushing force averaged around $70 \mathrm{kN}$ for aluminum and $190 \mathrm{kN}$ for titanium. These values are within the acceptable ranges for traditional metal foams. The FEA model, material properties, and even the main idea of designing shell elements for energy absorption have all been validated using relevant research papers. What awaits is the experimentation that could be done in the future when the opportunity arises. 


\section{References}

[1] D. Restrepo, N. D. Mankame, and P. D. Zavattieri, "Phase transforming cellular materials," Extrem. Mech. Lett., vol. 4, pp. 52-60, 2015.

[2] F. Tarlochan, F. Samer, A. M. S. Hamouda, S. Ramesh, and K. Khalid, "Design of thin wall structures for energy absorption applications: Enhancement of crashworthiness due to axial and oblique impact forces," Thin-Walled Struct., vol. 71, pp. 7-17, 2013.

[3] X. Wang and J. Shi, "Validation of Johnson-Cook plasticity and damage model using impact experiment," Int. J. Impact Eng., vol. 60, pp. 67-75, 2013.

[4] R. S. Yatnalkar, "Experimental Investigation of Plastic Deformation of Ti-6Al-4V under Various Loading Conditions," p. 81, 2010.

[5] A. S. Khan and H. Liu, "Variable strain rate sensitivity in an aluminum alloy: Response and constitutive modeling," Int. J. Plast., vol. 36, pp. 1-14, 2012.

[6] MatWeb, “Aluminum 2024-T4; 2024-T351.”. 


\section{Appendix}

\section{A. Summary of work done through UREP}

The UREP consisted of four phases. Phase 1 was for literature review. Phase 2 was for concept generation. Phase 3 was for simulation. Phase 4 was for experimentation. Out of many designs generated in phase 2, the following three were chosen based on their energy absorption properties for further investigation. To come up with the geometry the students consulted the literature and even used their individual creativity. Because there was no limit as to how the cellular structures could possibly look like, the students designed many complex shapes. However, through simulations many of these designs were weeded out and finally the best three designs were chosen. For this part, all parameters were kept constant and only the internal design of the cellular foam was varied.

From the understanding of folding mechanism of the cellular structure obtained from phase 2, the following final concepts were generated. In general, there are only three main concepts. For each of these concepts, four variations were generated by changing the strut thickness and wall thickness (See Figure 1). After it was found that geometry affects the energy absorption, it was decided to study the effects of strut thickness on energy absorption.

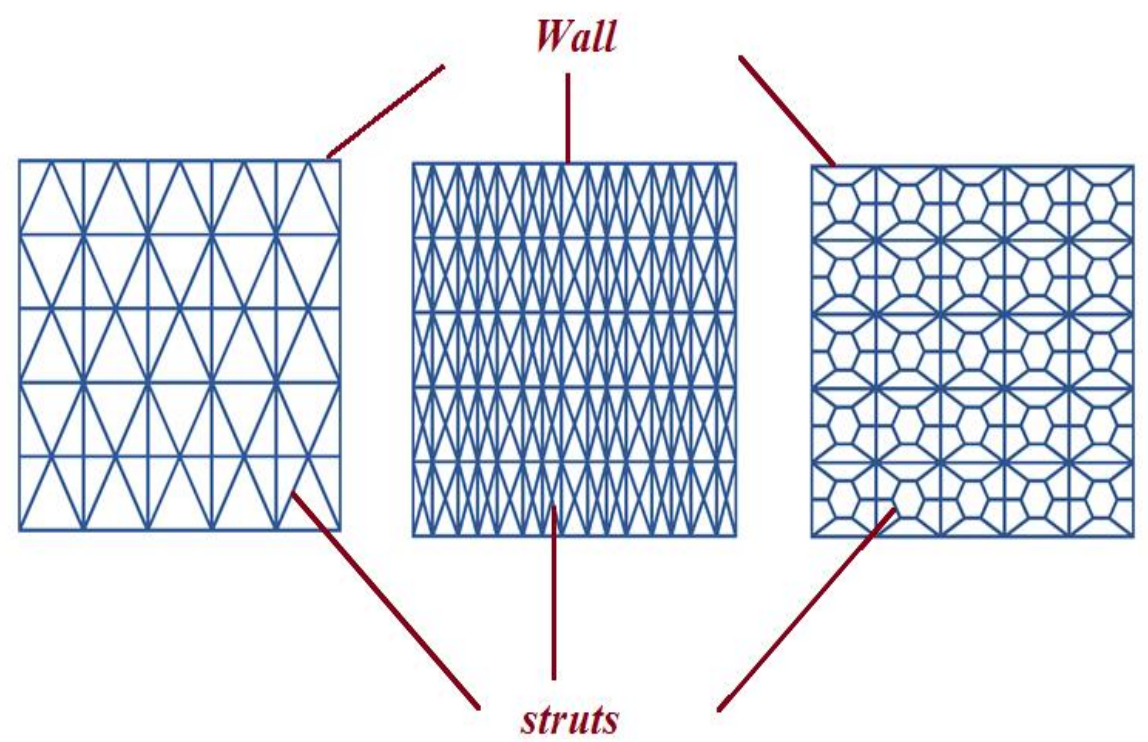

Figure 1: Three concepts evaluated in phase 3 (each concept with four variations)

The design of experiment used was full factorial design as shown in Table 1. The variations of these concepts can be found in the original report. These concepts were generated for lengths of $50 \mathrm{~mm}, 100 \mathrm{~mm}$ and $200 \mathrm{~mm}$. The cross section perimeter for all concepts is the same, which is $50 \mathrm{~mm} \times 50 \mathrm{~mm}$. 
Table 1: Design of Experiment for this study

\begin{tabular}{cccc}
\hline $\begin{array}{c}\text { Strut Thickness, } \\
\mathbf{T 1}(\mathbf{m m})\end{array}$ & $\begin{array}{c}\text { Wall Thickness, } \\
\mathbf{T 2}(\mathbf{m m})\end{array}$ & $\begin{array}{c}\text { Lengths, } \mathbf{L} \\
(\mathbf{m m})\end{array}$ & Material \\
\hline $0.5 \& 1.2$ & $0.5 \& 1.2$ & $50,100,200$ & $\begin{array}{c}\text { Aluminium and } \\
\text { Titanium }\end{array}$ \\
\hline & & & \\
\hline
\end{tabular}

Summary: A total of 72 samples (simulations runs)

Figures $2-4$ display the results of each of the concept in its four different variations. Figure 5 shows how the variations in strut thickness lead to different folding mechanisms.
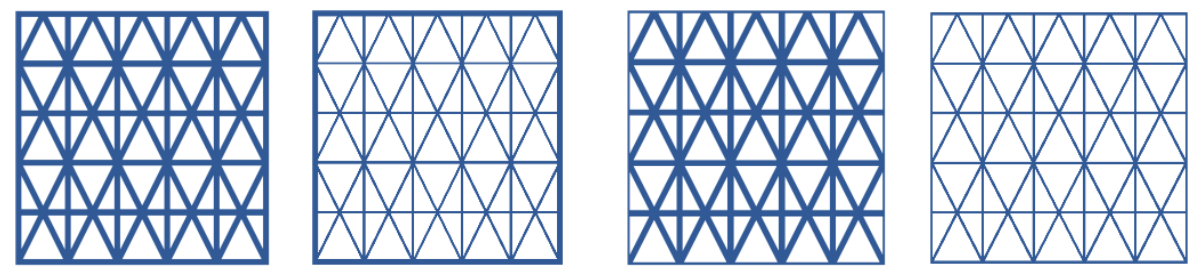

Figure 2: Concept 1 in four different variations due to the selected design variables
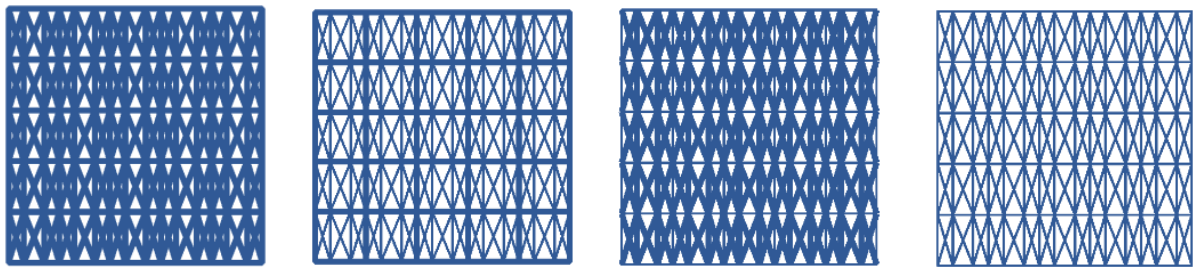

Figure 3: Concept 2 in four different variations due to the selected design variables
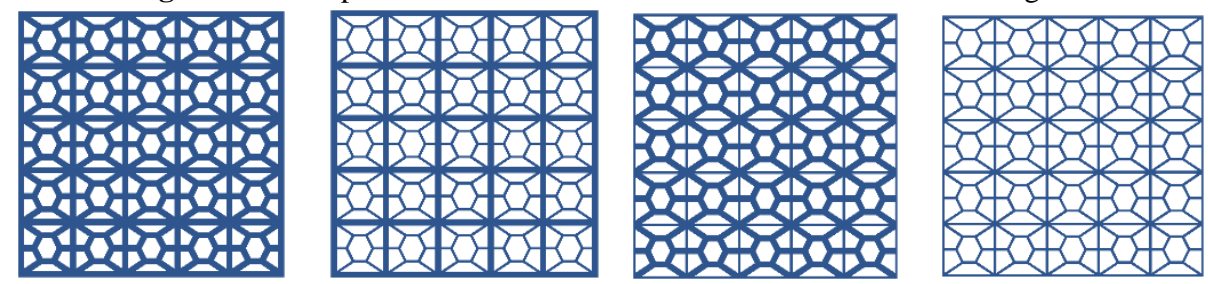

Figure 4: Concept 3 in four different variations due to the selected design variables 

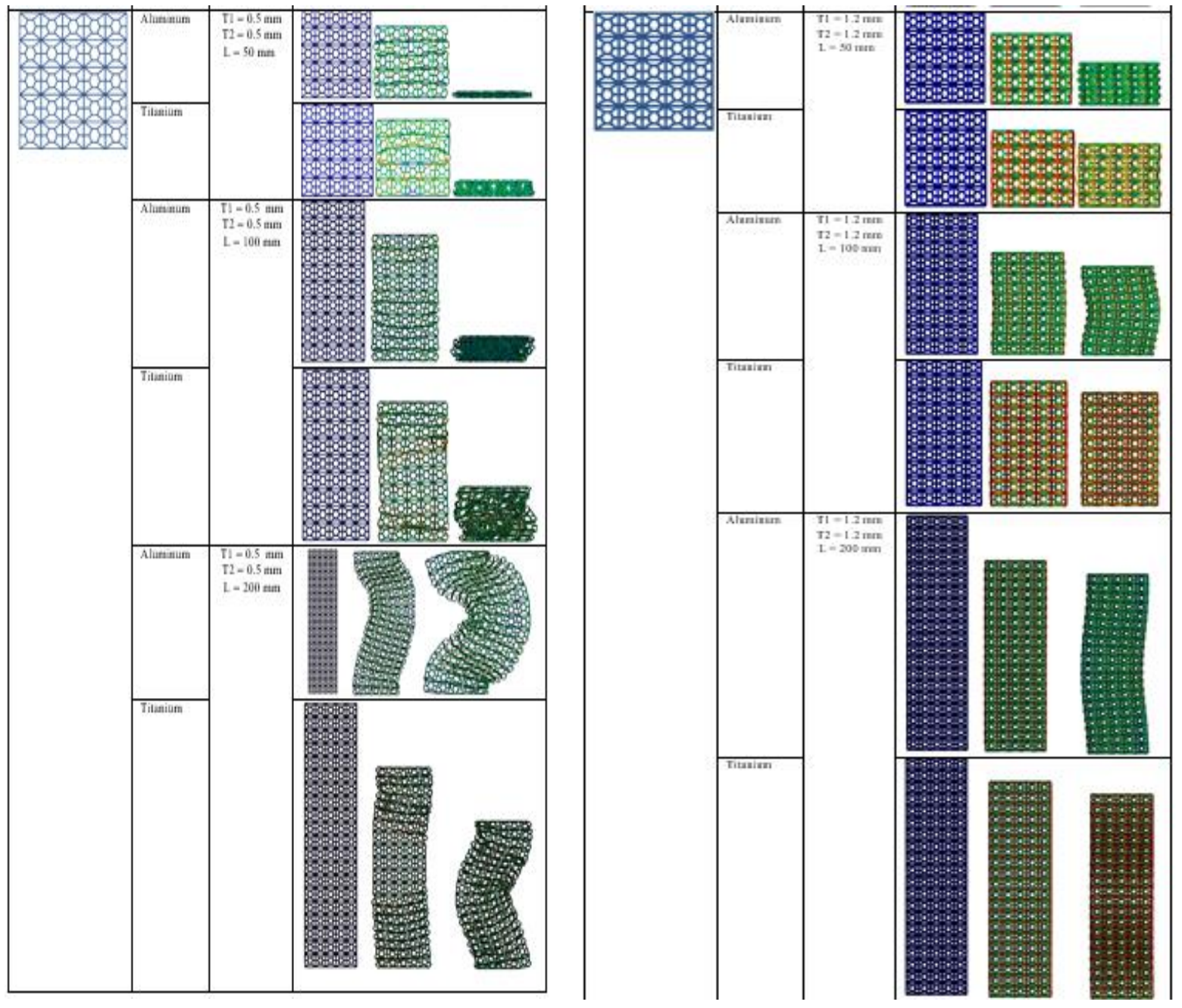

Figure 5: Different failure modes achieved with different strut thicknesses

Some of the main ideas from UREP results are as follow:

i. Geometry affects the energy absorption and folding mechanism when every other parameter is fixed.

ii. Even within the same geometry having different strut thicknesses affect the folding mechanism and the energy absorption.

Using the knowledge from these results, it may be possible to design cellular structures that fold in a certain way and have some desired energy absorption value. 


\section{B. Sample Eliminated Concepts}

The images below show some of the many concepts studied in this project.

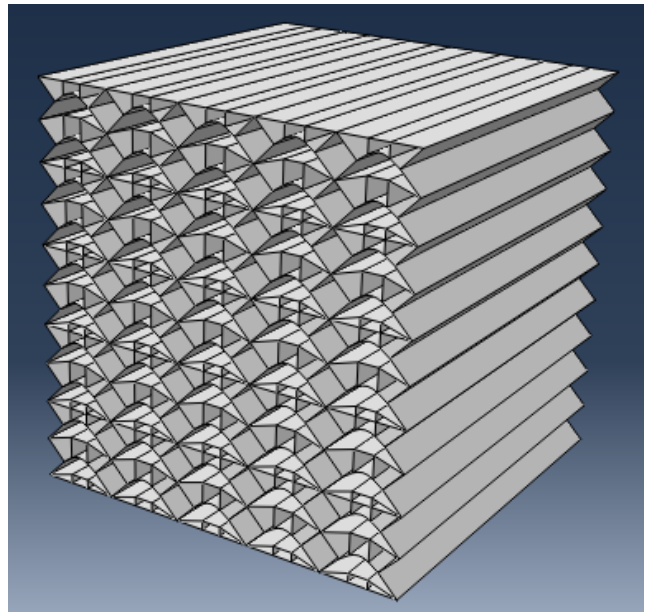

(a)

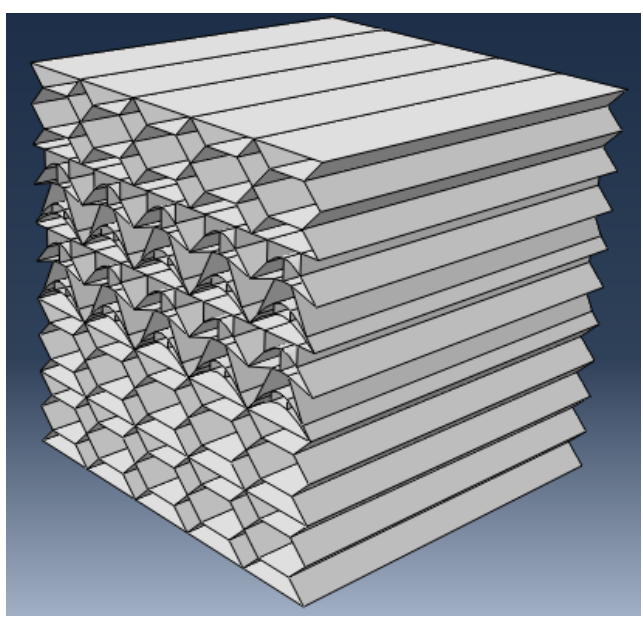

(C)

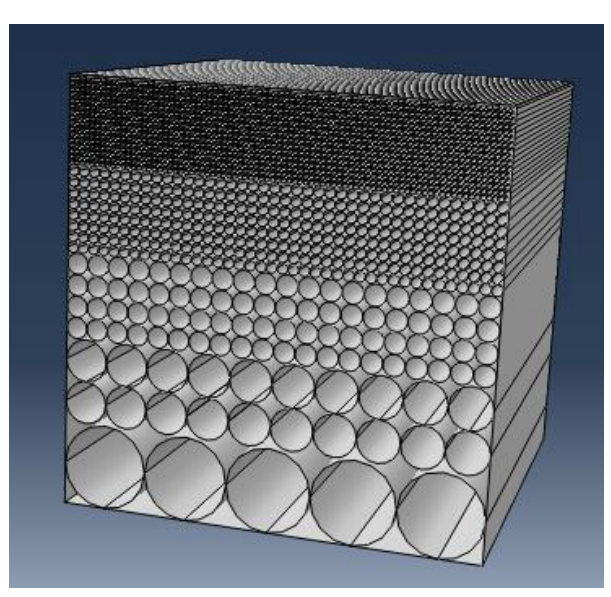

(e)

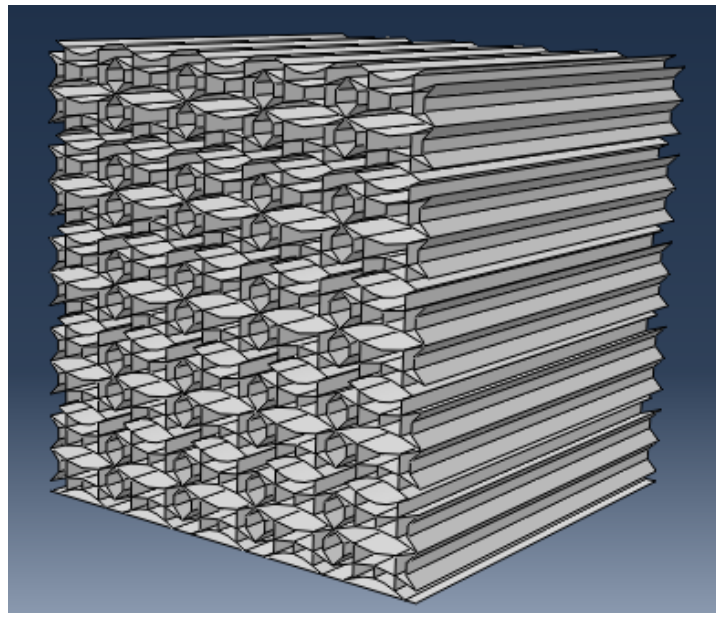

(b)

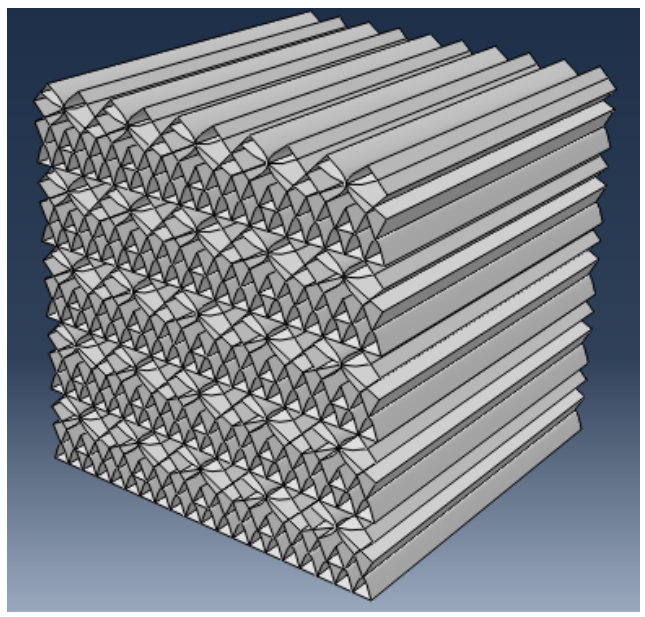

(d)

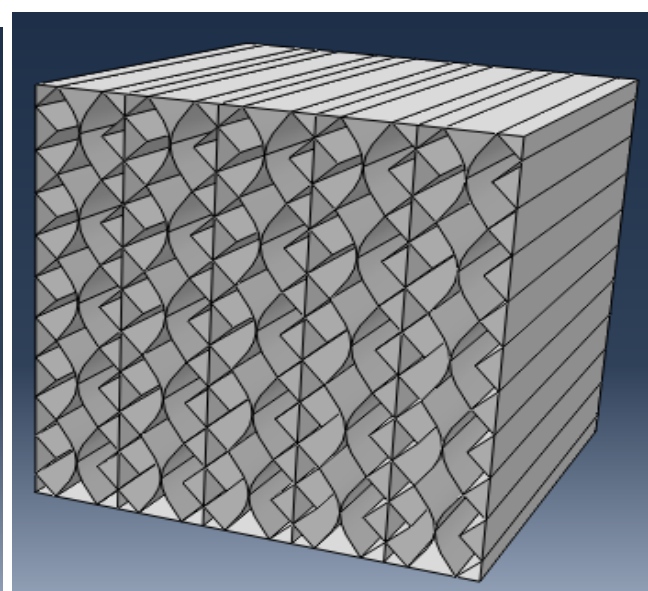

(f) 